\title{
A Chief Engineer's View of the NASA X-43A Scramjet Flight Test
}

\author{
Laurie A. Marshall ${ }^{*}$ and Griffin P. Corpening ${ }^{\dagger}$ \\ NASA Dryden Flight Research Center, Edwards, California, 93523-0273, USA \\ Robert Sherrill ${ }^{\ddagger}$ \\ NASA Langley Research Center, Hampton, Virginia, 23681-2199, USA
}

\begin{abstract}
This paper presents an overview of the preparation and execution of the first two flights of the NASA X-43A scramjet flight test project. The project consisted of three flights, two planned for Mach 7 and one for Mach 10. The first flight, conducted on June 2, 2001, was unsuccessful and resulted in a nine-month mishap investigation. A two-year return to flight effort ensued and concluded when the second Mach 7 flight was successfully conducted on March 27, 2004. The challenges faced by the project team as they prepared the first ever scramjet-powered airplane for flight are presented. Modifications made to the second flight vehicle as a result of the first flight failure and the return to flight activities are discussed. Flight results and lessons learned are also presented.
\end{abstract}

\section{Nomenclature}

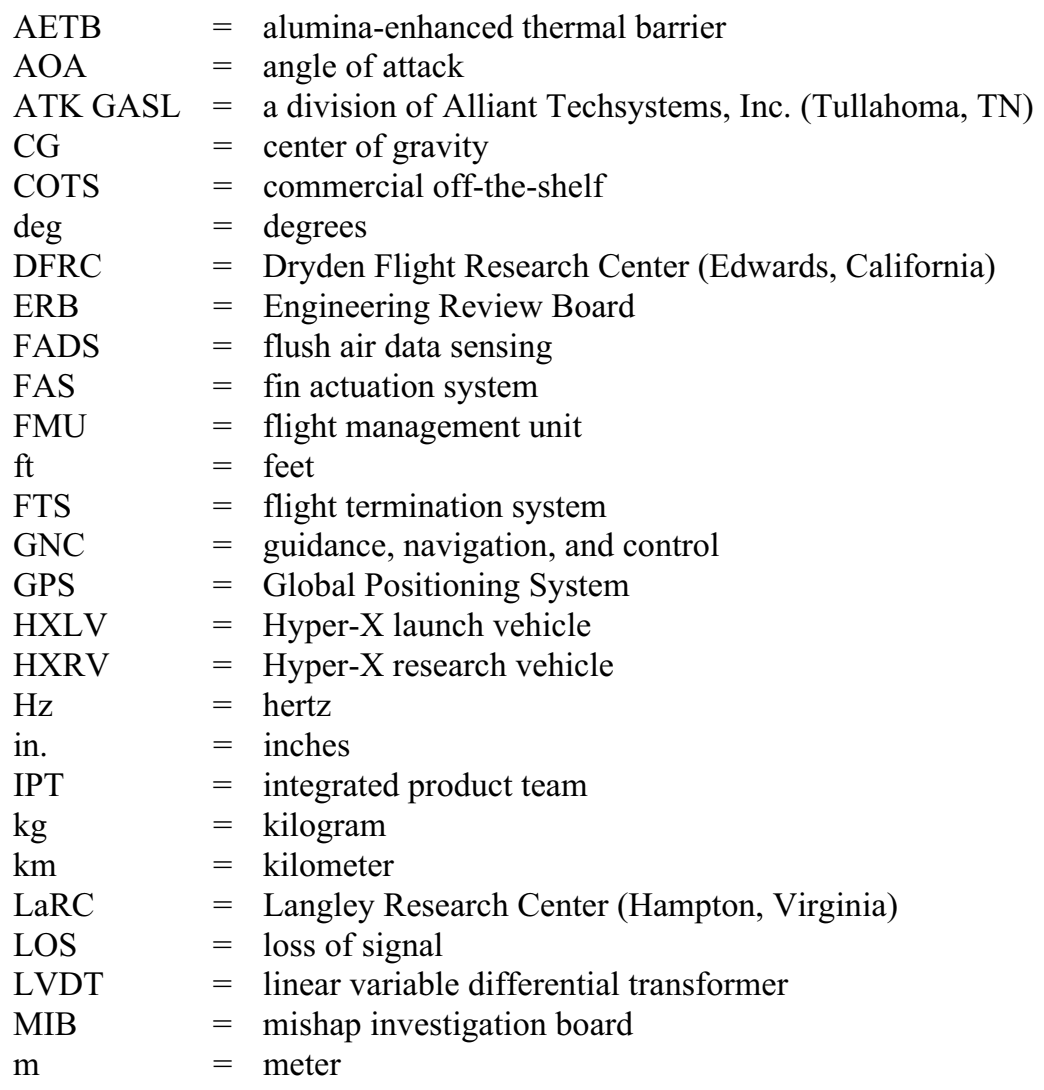

\footnotetext{
${ }^{*}$ Aerospace Engineer, Research Engineering, P.O. Box 273/Mail Stop D-2228, AIAA Member.

${ }^{\dagger}$ Aerospace Engineer, Research Engineering, P.O. Box 273/Mail Stop 4840H, AIAA Member.

*Aerospace Engineer, Research Engineering, Mail Stop 449, AIAA Member.
} 


$\begin{array}{ll}\mathrm{ms} & =\text { milliseconds } \\ \mathrm{N} & =\text { Newton } \\ \mathrm{NAWC-WD} & =\text { Naval Air Warfare Center Weapons Division (California) } \\ \mathrm{nmi} & =\text { nautical miles } \\ \text { OSC } & =\text { Orbital Sciences Corporation (Chandler, Arizona) } \\ \mathrm{P}-3 & =\text { Navy Orion Aircraft (data gathering aircraft) } \\ \mathrm{PID} & =\text { parameter identification } \\ \text { PSC } & =\text { propulsion system controller } \\ \text { PDT } & =\text { Pacific Daylight Time } \\ \text { POPU } & =\text { push-over-pull-up } \\ \text { psf } & =\text { pounds per square foot } \\ \text { PST } & =\text { Pacific Standard Time } \\ \text { RTD } & =\text { resistance temperature detectors } \\ \text { RTF } & =\text { return to flight } \\ \text { RV } & =\text { research vehicle } \\ \mathrm{S} & =\text { seconds } \\ \text { TPS } & =\text { Thermal Protection System } \\ \text { TUFI } & =\text { toughened unipiece fibrous insulation }\end{array}$

\section{Introduction}

$\mathrm{T}$ HE goal of the Hyper-X program has been to demonstrate and validate the technology, the experimental techniques, and the computation methods and tools for design and performance predictions of a hypersonic aircraft with an airframe-integrated, scramjet propulsion system. Three X-43A airframe-integrated scramjet research vehicles were designed and fabricated to achieve that goal by flight test; two test flights at Mach 7 and one test flight at Mach 10. ${ }^{1}$ The second Mach 7 vehicle is pictured in Fig. 1. The partners in this multiorganization project were NASA Langley Research Center (LaRC), NASA Dryden Flight Research Center (DFRC), Alliant Techsystems Inc., GASL division (ATK GASL), Orbital Sciences Corporation (OSC), and Boeing (Seal Beach, California). NASA was responsible and the lead for (1) the research vehicle design (lines), (2) aerodynamic and propulsion wind tunnel testing and CFD to support flight test risk reduction, (3) the aerodynamic and propulsion databases, (4) flight simulation, (5) vehicle validation and verification testing, (6) vehicle integration, (7) flight preparation, and (8) flight testing. The development and fabrication of the X-43A or Hyper-X research vehicle (HXRV) and the research vehicle (RV) adapter were the responsibility of ATK GASL and Boeing. Orbital Sciences Corporation in Chandler, $\mathrm{AZ}$ was responsible for the design, development, fabrication, and test of the Hyper-X launch vehicle (HXLV).

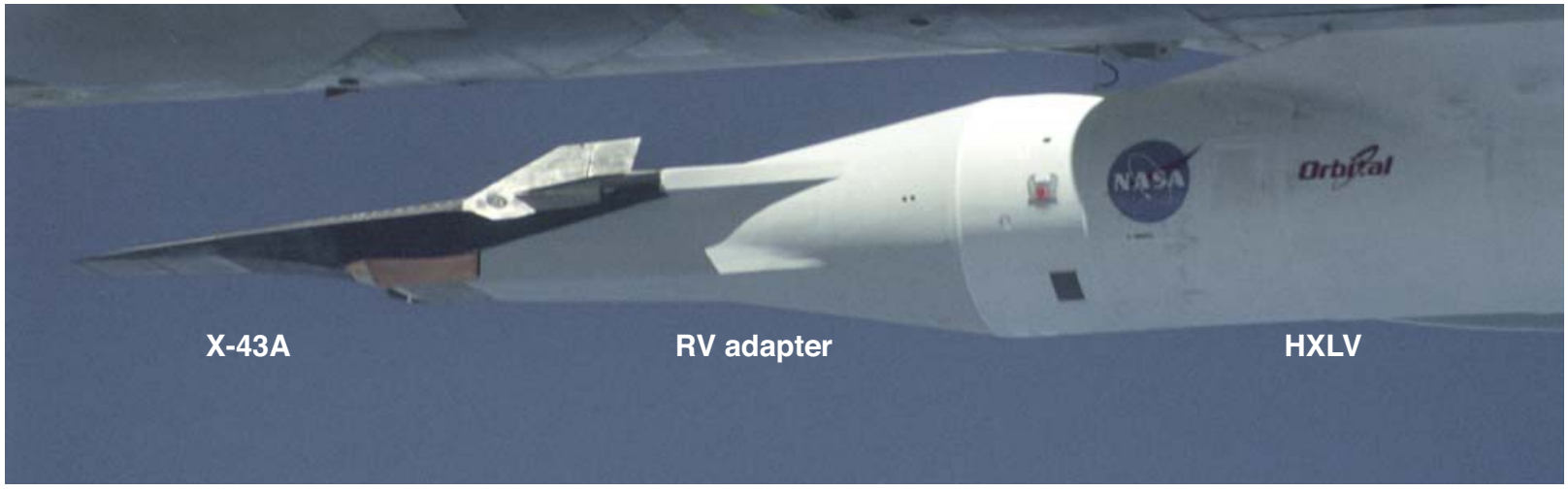

Figure 1. The X-43A ship 2, March 27, 2004.

The HXLV, a modified first-stage Pegasus ${ }^{\circledR}$ booster, launched the Hyper-X research vehicle to the separation conditions. The Hyper-X launch vehicle mated to the HXRV by the research vehicle adapter is known as the "Hyper-X stack," which was air-launched from the NASA B-52B carrier aircraft in the Naval Air Warfare Center Weapons Division (NAWC-WD) Sea Test Range off the coast of California.

The first Mach 7 flight of the X-43A was attempted on June 2, 2001 and experienced a failure during the boost phase of the mission when the HXLV departed from controlled flight. A nine-month mishap investigation ensued 
followed by a two-year return-to-flight (RTF) effort. The second Mach 7 flight was successfully completed on March 27, 2004. This report provides an overview of the first and second vehicles, the challenges faced by the project team in the preparation and execution of the two missions, and the lessons learned from a failure that allowed for success.

\section{Mission Description}

The X-43A mission consisted of four flight phases: B-52 Carried Flight, HXLV Boost, HXRV Separation, and HXRV Free Flight. Both the engine test and vehicle descent occurred during the HXRV Free Flight phase. Flights originated at NASA DFRC at Edwards Air Force Base in California. Figure 2 depicts a representative Hyper-X mission profile. The NASA B-52B, tail number 008, carried the Hyper-X stack to the designated launch point approximately $50 \mathrm{nmi}(92.6 \mathrm{~km})$ off the southern California coast where the stack was released. Five seconds after release from the B-52, the HXLV booster ignited and carried the X-43A along a predetermined trajectory to the designated separation conditions. Following booster burnout, the X-43A was separated from the RV adapter by four explosive bolts and two pyrotechnically pressurized pistons to begin the free-flight phase and scramjet engine experiment. Approximately 2.5 seconds after separation, the HXRV engine cowl door opened to obtain 5 seconds of fuel-off performance baseline data. The engine then ignited and operated for approximately 11 seconds. Following engine operation the HXRV obtained an additional 4 seconds of fuel-off performance data before performing a 17-second parameter identification (PID) maneuver, after which the cowl door was commanded closed. Following the engine test sequence, the X-43A performed a recovery maneuver to begin the controlled predetermined descent trajectory to low subsonic speed. During the descent, parameter identification, push-over-pull-up (POPU), and frequency sweep maneuvers were performed to assess aerodynamic characteristics and open-loop frequency response. The X-43A splashed down beyond the NAWC-WD Sea Test Range in the open ocean and was not recovered.

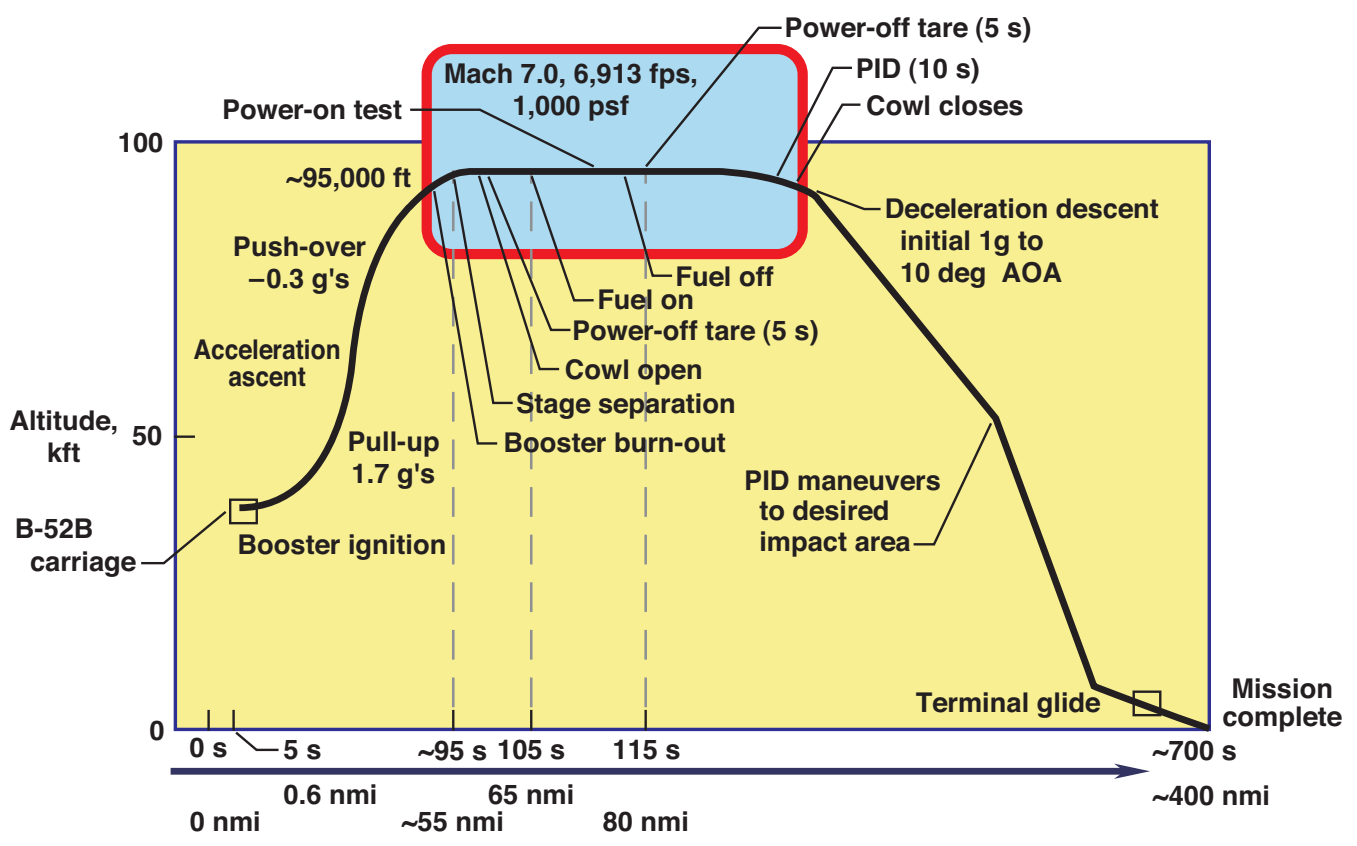

Figure 2. The X-43A Mach 7 mission profile.

\section{Mission Objectives}

The primary objective of the X-43A project was to demonstrate the performance of an airframe-integrated, scramjet-powered vehicle at selected test conditions. Data were acquired to verify scramjet, aerodynamics, and stability and control performance predictions as well as to perform flight correlation of the ground-based experimental data. In addition, data were acquired to verify the hypersonic vehicle structural integrity and system design. The minimum success criteria for flight were to successfully complete the mission through the fueled and unfueled portions of the scramjet engine experiment and to obtain data. Additional research objectives included: 
vehicle acceleration during the scramjet propulsion experiment and obtaining X-43A aerodynamic, structural, and guidance, navigation, and control (GNC) data until splash.

\section{Vehicle Description}

The X-43A vehicle was approximately 12 feet long $(3.66 \mathrm{~m}), 5$ feet wide $(1.52 \mathrm{~m}), 2$ feet high $(0.61 \mathrm{~m})$, and weighed approximately 3000 pounds (13,345 N). Figure 3 shows both the external (Fig. 3(a)) and internal (Fig. 3(b)) vehicle configuration. The X-43A was powered by a hydrogen-fueled, airframe-integrated scramjet propulsion system. This engine uses gaseous silane $\left(\mathrm{SiH}_{4}\right)$ as the ignition source for the hydrogen fuel. In order to prevent oxygen intrusion within the vehicle, nitrogen gas was used to maintain an inert environment and to pressurize the $\mathrm{X}-43 \mathrm{~A}$ internal cavities. The nitrogen gas was stored in tanks in the RV adapter for use during boost and within the $\mathrm{X}-43 \mathrm{~A}$ for use during the engine test. The high heat loads experienced during these portions of the flight, required that the engine leading edges be kept cool. The stored nitrogen gas was also used as a coolant pressurant to move coolant to the engine leading edges. An ethylene glycol-water mixture in the RV adapter served as the coolant during boost, while water only, located in the HXRV, was used as coolant during the engine test.

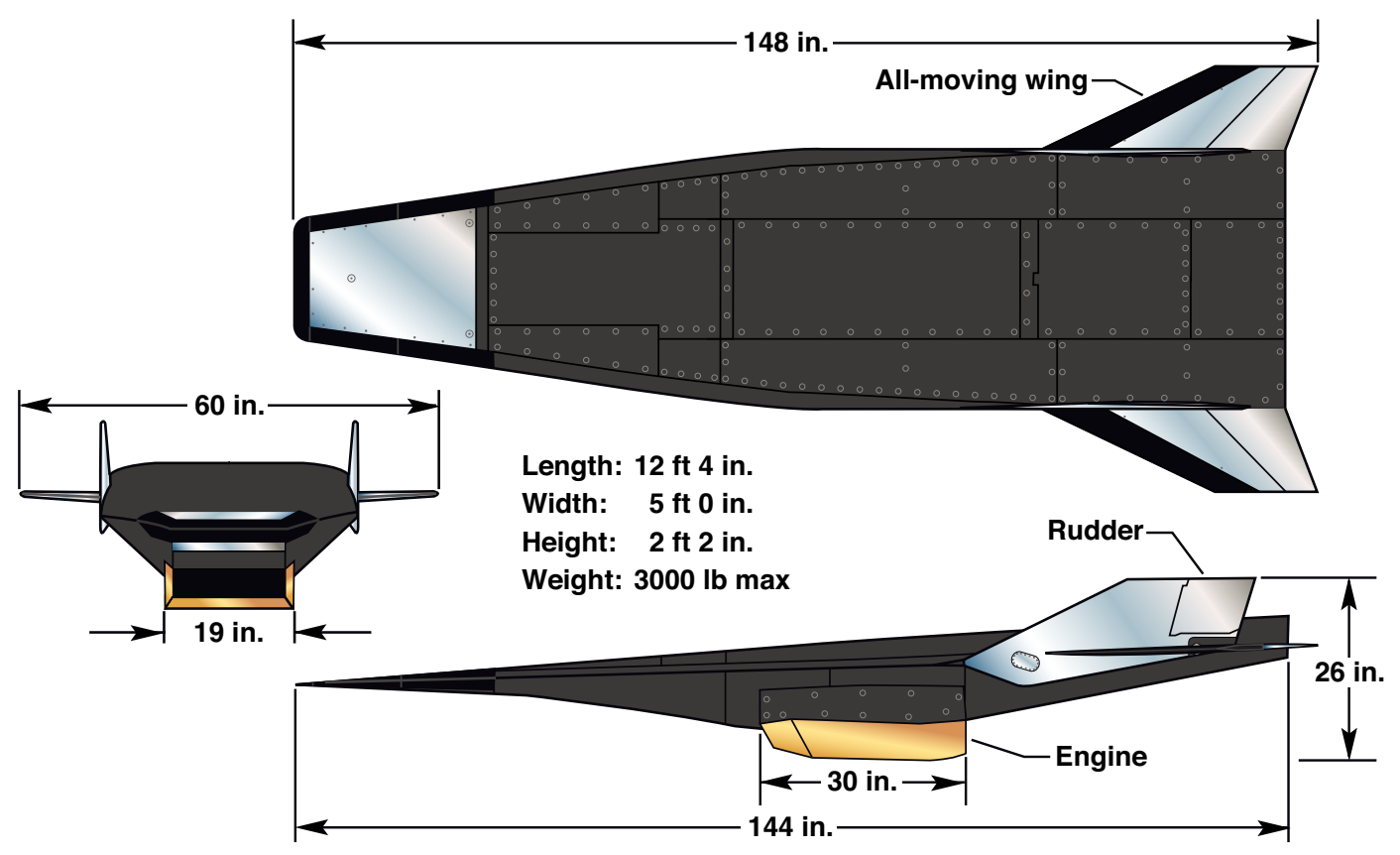

a) External.

Figure 3. The $X-43 A$ vehicle configuration. 


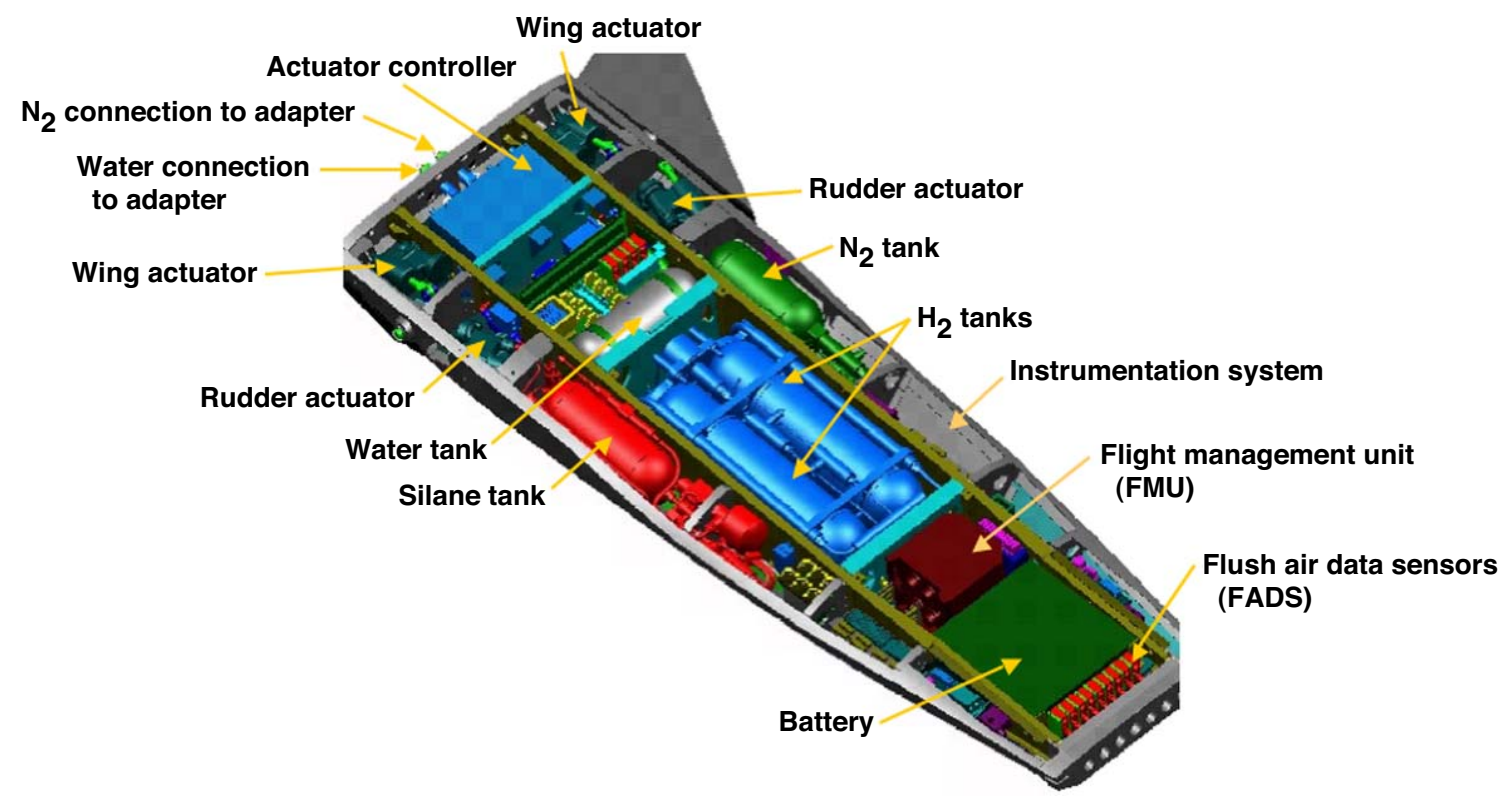

b) Internal.

Figure 3. Concluded.

\section{A. Management and Control Systems and Material Layout}

The vehicle management and control systems consisted of five electromechanical actuators, controlled by a single electromagnetic actuator controller (Fig. 3(b)) and a flight management unit (FMU). The actuators operate two all-moving wings, two rudders, and the cowl door. The FMU integrates the functions of navigation, flight control sensors, and mission computer into one unit.

The vehicle material layout is shown in Fig. 4. The airframe is primarily a steel and aluminum structure protected by alumina-enhanced thermal barrier (AETB) tiles coated with toughened unipiece fibrous insulation (TUFI). The edges around the nose and wing leading edges are carbon-carbon composites. The control surfaces consist of Haynes alloy skins and rib structures. The vehicle nose is made of tungsten. The engine is constructed primarily of a copper alloy and has water-cooled leading edges.

\section{B. Instrumentation System}

The instrumentation system, used for data acquisition, was comprised of the sensors, wires, connectors, electronics, and software necessary to acquire and transmit data from the HXRV to both airborne and ground-based receiving sites for recording and real-time monitoring. The X-43A flights travel past the range for data acquisition by ground-based assets. As a result, data gathering aircraft were required to supplement ground information to allow capture of data for the entire flight. A best source selector, located at NASA DFRC, was used to identify the telemetry asset (ground or airborne) with the best data during the mission.

Prior to launch from the B-52, the data from the instrumentation system was used to monitor and evaluate the vehicle systems health to determine if the vehicle was ready for launch. The X-43A vehicle instrumentation system sensors consisted of pressure transducers, strain gages, thermocouples, and resistance temperature detectors (RTD). In addition, there were miscellaneous analog measurements from electrolytic oxygen sensors, inductive current sensors, and voltage dividers, as well as serial data from the FMU via a 1553 data bus interface. A list of the sensors used, organized by measurement type is shown in table 1 . 


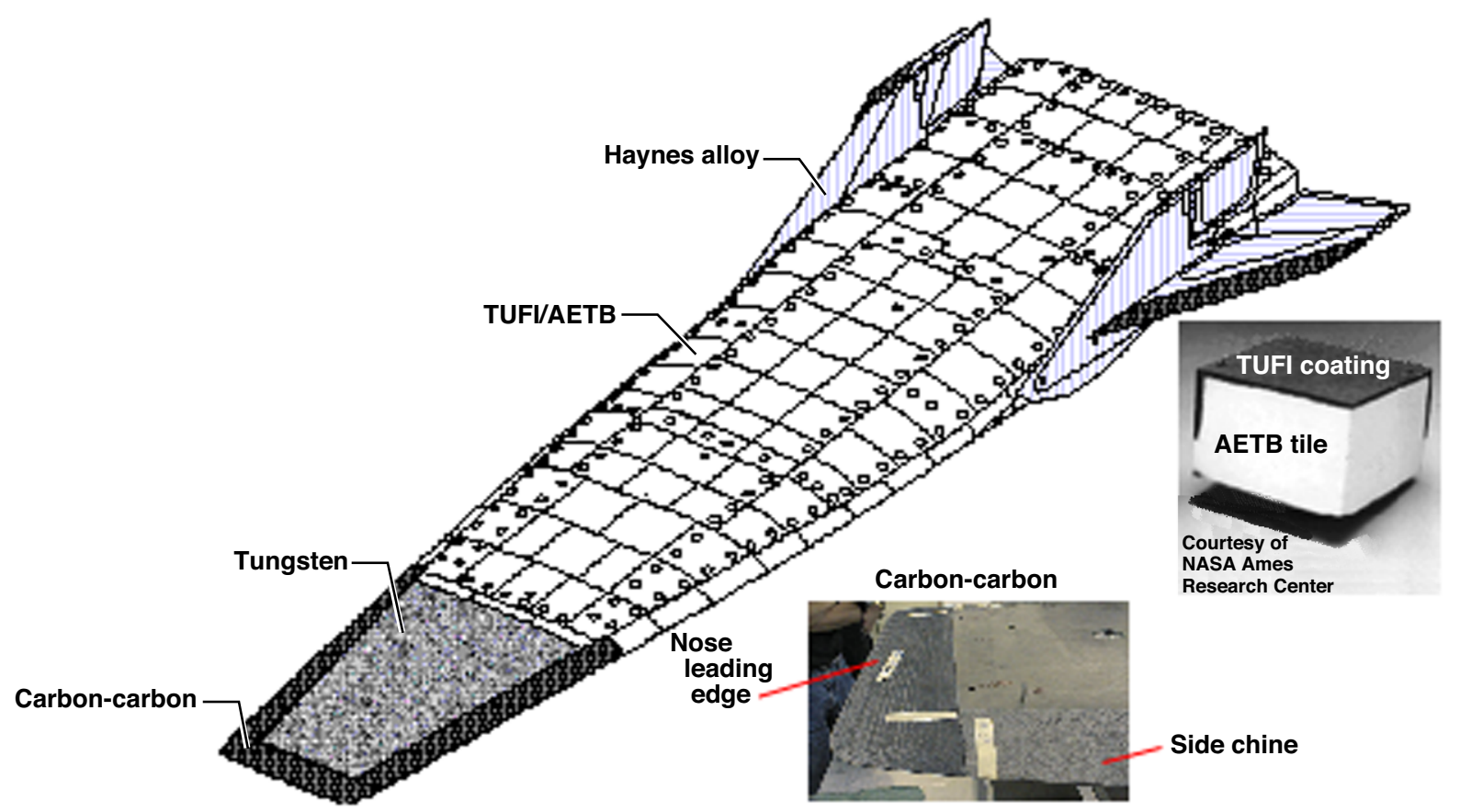

Figure 4. Vehicle material layout.

Table 1. Instrumentation summary.

\begin{tabular}{lrl}
\hline \hline \multicolumn{1}{c}{ Measurement type } & HXRV & \\
\hline Embedded time code* & 6 & \\
Pressures & 175 & \\
Strain gages & 14 & \\
Temperatures & 113 & \\
Miscellaneous analog & 9 & \\
1553 data bus (450 16-bit words) & 792 & (unique parameters) \\
\hline Total & 1109 & \\
\hline * X-43A vehicle 2 only. & &
\end{tabular}

\section{Flight 1 Preparation Challenges}

Two aspects of the X-43A mission, the stage separation and the engine test, were considered high risk. The primary objective of the first flight was to reduce the risk in these areas and thereby increase the probability of success for flights 2 and 3. This line of thinking demonstrates the largest challenge associated with the X-43A, the challenge of designing a vehicle that would have to do several tasks that had never been done before. High dynamic pressure, high Mach number, and stage separation of two nonsymmetric vehicles was one such event. The approach the project team took to prepare for the unique separation, and their efforts to understand how the vehicle would 
perform during the stage separation event provide the best example of how this project team attacked such challenges. To increase confidence in the success of this operation, several tests were performed. An extensive fullinterference stage separation wind tunnel test at Arnold Engineering Development Center (AEDC) (Arnold AFB, Tullahoma, Tennessee) provided a large portion of data for use in the separation aerodynamics model. Figure 5 shows the two wind tunnel models used in this test installed in the test section. The first model was of the HXLV mated to the RV adapter and the second model was of the X-43A. During the test run the separation distance between the wind tunnel models could be varied. This provided data on the interference effects and influences each vehicle would have on the other as the X-43A separated from the RV adapter. Additional wind tunnel tests performed at NASA LaRC and computational fluid dynamics analysis also provided data for the separation aerodynamics model and database. Furthermore, an ejector piston test was performed at OSC in Chandler, AZ. In this test, two blocks represented the mass of the X-43A and the RV adapter mated to the HXLV, respectively. The blocks had air cushions on each corner that allowed nearly frictionless movement. The purpose of the test was to assess the performance of the two pyrotechnically pressurized pistons installed in-between the blocks and gather data for use in the development of a separation piston model. Both the aerodynamic model and the piston model were used in the twelve (6+6) degree-of-freedom separation simulation that modeled both the HXRV and HXLV mated to the RV adapter. In addition to the ejector piston test, large-scale hardware testing included a full-scale separation test, also performed in Chandler, AZ. In that full-scale test the second X-43A vehicle airframe, ballasted for flight weight and center-of-gravity (CG) location, was mated to the first vehicle RV adapter and the separation systems were tested. The purpose of this test was to demonstrate that the mechanical systems would function as expected and also provide data for the validation of the separation simulation. ${ }^{2}$ This full-scale test also allowed testing of an adapter camera, which successfully captured the event.

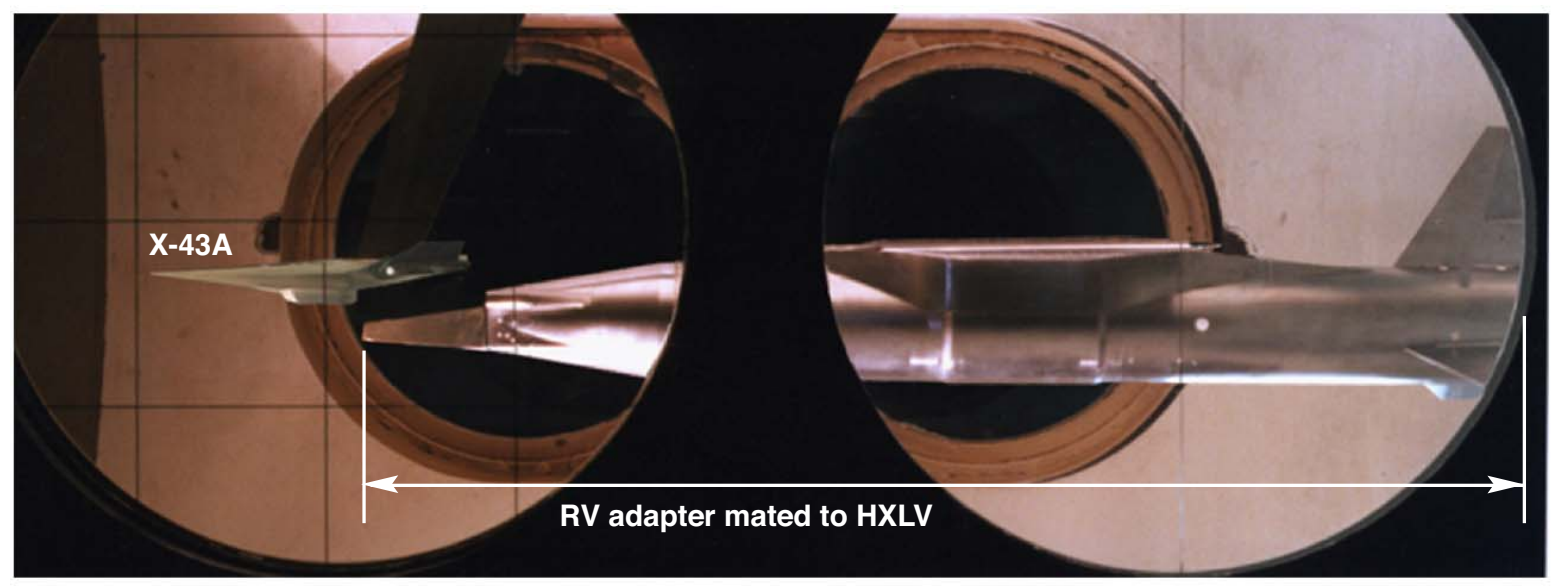

Figure 5. The AEDC stage separation wind tunnel test models.

In addition to the extensive scramjet engine research and hypersonic vehicle design work performed over the years, the X-43A project was also able to make use of data and analysis from both the X-30 program and a Mach 10 global reach vision vehicle. The X-43A flights targeted two key flight conditions for the scramjet-powered vision vehicle: Mach 7 and Mach 10. Mach 7 represented a trajectory point where the vision vehicle ${ }^{3}$ was in accelerating flight, had a relatively good thrust margin, few flight scaling issues, and the design was supported by a large quantity of wind tunnel experimental data. Mach 10 was selected because this was the top (cruise) speed for the vision vehicle, and ground facilities were limited to milliseconds (ms) of test time. Studies showed that a $10-(3.05 \mathrm{~m})$ to 12 -foot-long $(3.66 \mathrm{~m})$ vehicle could be scaled down from the 200 -foot-long $(60.96 \mathrm{~m})$ Mach 10 cruiser and still demonstrate scramjet-powered acceleration. ${ }^{1}$ The size of the X-43A was determined by those studies, however the project was challenged to get all the necessary systems to fit inside of such a small compact vehicle. Not only did the vehicle size impact the component size of the systems installed in the vehicle, but it also presented some unique maintenance and test challenges.

For the X-43A free flight phase, the primary portion of the mission was from separation, through the engine test, to cowl closed. Since that was the focus of the experiment, the project could have ceased all work and analysis at that point in the trajectory. Instead, determined to obtain the most information possible from the flight, the descent phase of the mission and the additional research maneuvers were developed. This required additional work in the 
areas of aerodynamics and GNC from both a research maneuver design standpoint and from the position of model, guidance, and controller development. Even though some work was done for the descent phase, success during that portion of the flight was still considered a secondary objective and the research vehicle design requirements were specified in terms of the primary portion of the mission. As such, thermal and structural analyses were not performed for the descent phase of the flight.

A project level launch vehicle decision was made with regard to the boost phase of the trajectory. The use of a modified first-stage Pegasus booster on the launch vehicle presented a challenge for the Mach 7 flights. On a typical Pegasus mission with the standard launch conditions of Mach 0.8 at an altitude of 40,000 ft $(12.19 \mathrm{~km})$, the first stage separates at speeds in excess of Mach 7. Since the X-43A decelerates very little between separation and the engine test, the desired separation Mach number was essentially Mach 7. In order to separate at this condition, the additional booster energy would have to be bled off. The project chose to launch at a lower altitude, 24,000 ft $(7.32 \mathrm{~km})$, and speed, 0.5 Mach number, than the standard Pegasus launch conditions to bleed off the excess energy and hit the desired separation conditions.

\section{Flight 1 Summary}

The first flight of the X-43A began at 13:43 PDT on June 2, 2001, when the HXLV was successfully released from the B-52B, tail number 008. Almost immediately following launch the X-43A engine cowl door linkage load measurements exhibited anomalous readings. These readings were isolated to the cowl door strain gages and did not have any impact on the rest of the Hyper-X stack or the flight.

HXLV motor ignition occurred as planned, 5 seconds after launch. Approximately one second later, the RV adapter nitrogen valve opened to allow the gaseous nitrogen to pressurize the X-43A internal cavities and maintain an inert environment. The high-pressure nitrogen gas flowed through a regulator to reduce the pressure before going into the HXRV. Seven seconds after launch, the regulator malfunctioned, the high-pressure gas exceeded the relief valve pressures, and nitrogen began venting out of the side of the RV adapter.

Approximately 11.5 seconds after launch, during the HXLV pitch-up maneuver, a $2.5 \mathrm{~Hz}$ roll oscillation developed, that was unrelated to the RV adapter nitrogen venting. ${ }^{4}$ The current limit on the rudder actuator was reached 13 seconds after launch and the rudder no longer responded to commands. Shortly after this event, the starboard fin departed from the vehicle, followed by the port fin, then rudder, and finally the wing. Approximately 18 seconds after launch, the X-43A left wing linkage failed. The HXLV flight termination system was initiated 48 seconds after launch, which blew a hole in the HXLV motor case reducing thrust to zero. The shock from the flight termination system (FTS) ordnance explosion caused the uncommanded separation of the X-43A from the RV adapter. Both the "separation" and the failed wing linkage were captured on video by the RV adapter cameras. The X-43A continued to transmit data until 77 seconds after launch, which is the approximate time it hit the water. ${ }^{4}$

\section{Mishap Investigation}

Immediately following flight 1 , a mishap investigation board (MIB) was appointed and began the investigation on June 5,2001. The project team worked with the MIB by performing tests and analyses, in an attempt to identify the root cause of the mishap. Because of the familiarity with the vehicle and systems, the project team was in the best position to do analyses and obtain information quickly. However, it was difficult for the team to be a part of the investigation to uncover deficiencies in areas in which they were responsible and that perhaps could have been identified earlier. During the nine-month investigation, all aspects of the Hyper-X project fault tree were evaluated and closed out. The primary activities focused on the launch vehicle in the area of loss of control resulting from aerodynamics and controls. However, because of the other anomalies identified during the flight, the HXRV and the RV adapter portions of the fault tree were also explored. The MIB report root cause specified that the "HXLV failed because the vehicle control system design was deficient for the trajectory flown due to inaccurate analytical models". The MIB cited deficiencies in the modeling of the HXLV aerodynamics, in actuator compliance, and in the actuator system as contributors to the flight 1 failure. In addition to the root cause, the mishap investigation report also identified some programmatic and technically significant observations, findings, and recommendations. An extensive level of effort was required to identify the root cause of the mishap and the other anomalies. In the end, it was useful that the project team members had been such active participants in the investigation. As a result, project members learned lessons first hand, which allowed them to identify similar shortcomings as they began the RTF effort and flight 2 preparation activities. 


\section{Return to Flight: Preparation of Flight 2}

The recommendations and observations identified by the MIB served as the starting point in the RTF activities. As part of the mishap investigation report, the project team was responsible for developing a list of corrective actions in response to the recommendations and observations provided.

\section{A. Return to Flight Activities}

In an attempt to respond to the programmatic observations, the project added new layers of communication and review in the form of integrated product teams (IPT), an engineering review board (ERB), and peer assessors. At the working level, IPTs were formed for each discipline or critical development area with representatives, where appropriate, from each organization. The IPTs all participated in the ERB led by the project chief engineer. The ERB provided technical direction to the project to ensure mission success and interfaced with project and program management in addition to the IPTs. The peer assessors provided continuous independent technical assessment and review of the technical approach, decisions, and analyses; each within their specific discipline.

With the new levels of communication in place, the project was in a better position to address the technical recommendations and observations identified during the mishap investigation. The new structure also allowed the project to better assess other risk areas and move forward in the wake of the lessons learned from flight 1 . The MIB technical observations, findings, and recommendations mainly focused on the HXLV, but some deficiencies on the HXRV were also noted. The IPTs were tasked with identifying the methods that the project would employ, to either eliminate these issues or ensure that the vehicle was robust to these concerns for the second flight. The IPTs were not limited to the issues and areas identified by the MIB. They were also tasked with evaluating the entire mission, including all flight phases and ground operations to identify the risk areas in hardware, software, analysis, and documentation, i.e. interface control documents, project processes, test procedures, and reports. In addition to being categorized by mission phase, as the risks were identified they were also assigned to the respective IPTs. Figures 6(a) and 6(b) show the breakdown of the risks by IPT and mission phase, respectively. Although the flight 1 mishap primarily affected the launch vehicle, Fig. 6(b) demonstrates how much effort was expended looking at the other phases of flight as well. The probability of occurrence and magnitude of impact were evaluated for each risk and mitigations for these were identified. Most of the RTF effort was spent on the risk reduction activities that were derived from these mitigations. Mitigations included additional testing and analysis for hardware and software, model and uncertainties evaluation, update and enhancement, and independent simulations and review where appropriate. The risks and corrective actions served as the foundation for the RTF activities that primarily focused on risk reduction for all phases of X-43A flight.

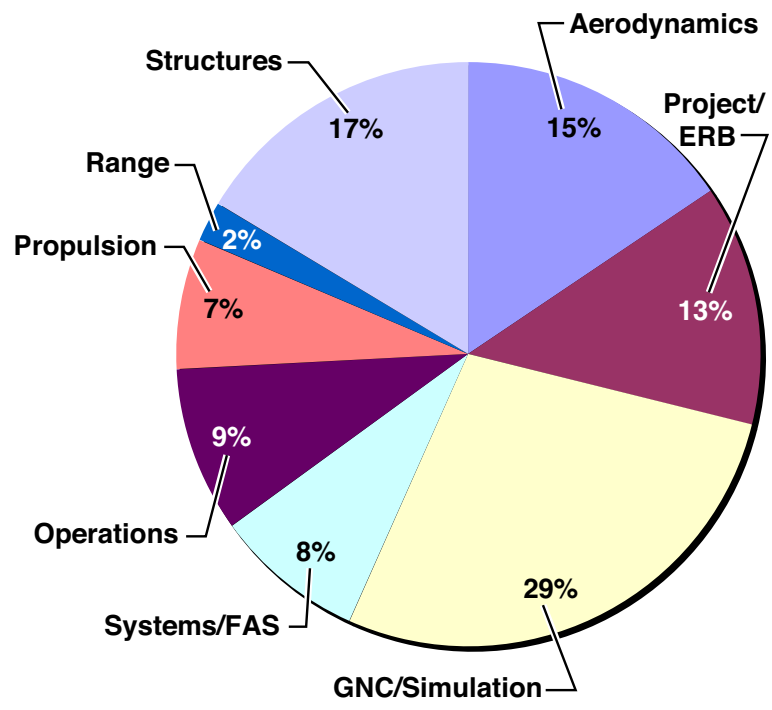

a) Categorized by integrated product team.

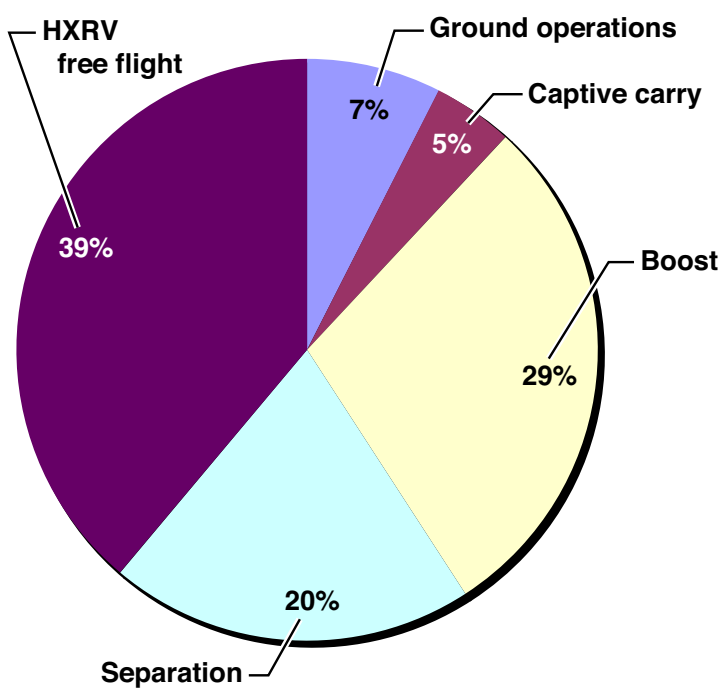

b) Categorized by mission phase.

Figure 6. Return to flight risk evaluation. 


\section{B. Risk Reduction Activities}

The launch vehicle experienced the largest modifications during the RTF effort in the form of both hardware and software modifications. The software and models benefited from 11 new wind tunnel entries and analyses performed during the mishap investigation and subsequent RTF activities. Both the aerodynamics and fin actuation system (FAS) models received extensive updates. The autopilot was also reexamined to identify potential updates. The hardware also received substantial improvements in the form of propellant offload and the FAS. In order to fly a more Pegasus-like trajectory while still maintaining a Mach 7 separation condition, approximately $3400 \mathrm{lb}$ $(1542 \mathrm{~kg})$ of solid rocket propellant was removed from the HXLV motor. This allowed a launch at an altitude of 40,000 feet $(12.19 \mathrm{~km})$ at approximately 0.8 Mach number, so that the transonic dynamic pressure was reduced and the resulting fin loads were less than flight 1 . Figure 7 provides a dynamic pressure comparison of the flight 1 and flight 2 HXLV trajectories to a typical Pegasus first-stage boost. A 50-percent margin on the HXLV fin actuators was desired throughout the boost phase of the mission. In an attempt to achieve this increased margin, the FAS was redesigned. A second motor was added to each actuator (port, starboard, and rudder) to double the allowable hinge torques and to increase margin.

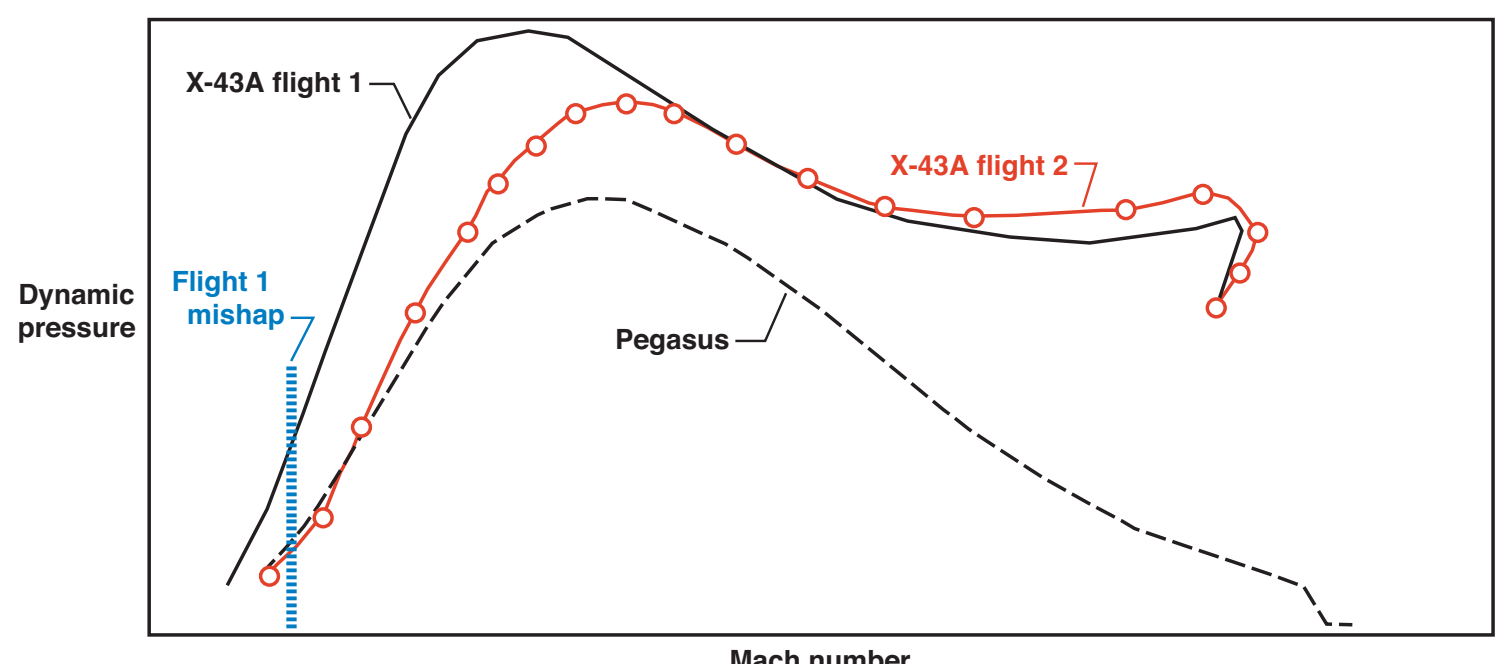

Figure 7. Boost trajectory comparison.

The examination of the research vehicle and RV adapter for all phases of flight, resulted in improvements throughout, from ground testing to splash. Procedures were updated and tests resequenced based on flight 1 preparation experience and lessons learned. Where appropriate, additional testing was performed that provided the data for new models with improved fidelity and ultimately software that yielded a vehicle that was more robust in response to disturbances and better able to predict the results in flight. New tests that resulted in model modifications included: an ejector piston test, cowl door calibration and free play testing, compliance and hysteresis testing, and system timing tests. The X-43A propulsion system controller (PSC) software also benefited from additional test data. The purpose of the PSC was to control the fuel delivery to the engine, minimize the risk of unstart or flameout, and to command the engine cowl door movement. ${ }^{5}$ The PSC was modified to improve overall mission success by increasing the robustness of the scramjet to unstart. This unstart protection known as "Durascram" was implemented to reduce the risk to mission success resulting from uncertainties in flight conditions, engine performance, and operability. Durascram, which was developed and tested using wind tunnel research, had the ability to continually adjust the fuel level to reduce the risk of unstart. The flight 2 PSC unstart protection algorithms were demonstrated to be more robust than the flight 1 PSC unstart protection. Another modification was made with regard to engine performance. Wind tunnel test results indicated that the chance of an engine flameout was higher at low angles of attack. In an attempt to reduce the potential of an engine flameout and increase the chances of successful engine operation, the nominal test angle of attack was slightly increased.

Independent simulations were developed for the boost and separation phases of flight to evaluate the incorporation of the new models with improved fidelity into the simulation and to provide a source for independent analysis. An independent review of the free-flight or HXRV simulation identified areas of improvement within the models and the simulation; all were addressed. 
In addition to these model and software modifications, anomalies related to the X-43A that occurred during flight 1 were addressed. The RV adapter nitrogen system regulator malfunction, the HXRV left wing linkage failure, and anomalous strain gage readings on the engine cowl door were the three primary X-43A and RV adapter hardware anomalies investigated as a result of the flight 1 mishap. Even though, these were not related to the mishap, they were identified as deficiencies that needed to be repaired to ensure a greater chance of mission success on the second flight.

When the RV adapter nitrogen system pressure regulator failed to regulate, the downstream pressures were not reduced to the expected levels. As a result, the system relief valve opened and vented the excess gas overboard. As with all the anomalies identified in the flight 1 mishap, fault tree analysis was performed to attempt to determine the cause of the regulator failure. Several potential causes were identified, including contamination, internal leakage, mechanical shock, and shockwave impingement from opening the upstream pyrovalve to release the nitrogen from the tank into the system lines. No single cause of the regulator failure was identified. However, all potential causes were addressed and mitigated by modifying cleanliness specifications and procedures, adding in-line filters, and replacing the original regulator design with one of a more robust design relative to particulate contamination and shockwave impingement.

During flight 1, the X-43A left wing linkage experienced a failure that allowed the wing to freely rotate about its spindle. The loads experienced during the flight 1 mishap were far in excess of the expected loads for the HXRV wings. Nevertheless, it was determined that the wing control horns, which connected the spindle to the actuator rod end, could benefit from a redesign. The original control horn design was a clamped installation made out of aluminum that allowed excessive slippage of the control horn about the spindle. The new pressed fit installation removed slippage, included key ways to improve shear transfer, and was made out of steel, which strengthened the control horns and increased their structural margins.

Immediately following the launch from the B-52, the strain gages on the cowl door actuator linkage indicated both tension and compression simultaneously. In order to effectively capture the link load measurements, one of the sensors was sensitive to axial compression and the other to tension. In addition to reading both states at the same time, the sensor sensitive to compression was indicating tension. Interference between the rod end and actuator crank was determined to be the cause of the anomalous strain gage readings. Furthermore, the radius between the forks and base in the actuator crank were determined to be an incorrect dimension. These radii were remachined to the correct dimension and installed. Subsequent testing indicated that the opposite direction load changes on the cowl door strain gages were eliminated with the removal of the interference.

\section{Flight 2 Summary and Results}

The flight test results presented provide an overview of the successful Mach 7 mission from launch to splash. These results serve as an introduction to the analyses performed by the specific engineering disciplines including aerodynamics, propulsion, GNC, flight systems, instrumentation, and structures.

\section{A. Boost}

The second flight of the X-43A began at 14:00 PST with a successful launch from the B-52B, tail number 008, on March 27, 2004. HXLV motor ignition occurred as planned, 5 seconds after launch. During the boost the HXLV maintained nominal attitude closely following the predicted boost trajectory. The RV adapter fluid systems performed as expected with the coolant and pressurant initiated 48 seconds into the boost to supply coolant to the scramjet engine and purge to the $\mathrm{X}-43 \mathrm{~A}$ internal cavities. The highest loads the $\mathrm{X}-43 \mathrm{~A}$ wings experienced during the primary portion of this mission occurred during boost in the push-over maneuver to negative angle of attack, as expected. Figure 8 shows the X-43A wing hinge moments and surface positions for the first 70 seconds during boost when the actuator brake was engaged. Ninety-three seconds after launch from the B-52, the HXLV delivered the $\mathrm{X}-43 \mathrm{~A}$ to the predetermined separation conditions. Table 2 demonstrates how close these conditions were to the predicted separation conditions. In all cases the flight separation conditions were within an acceptable tolerance. 

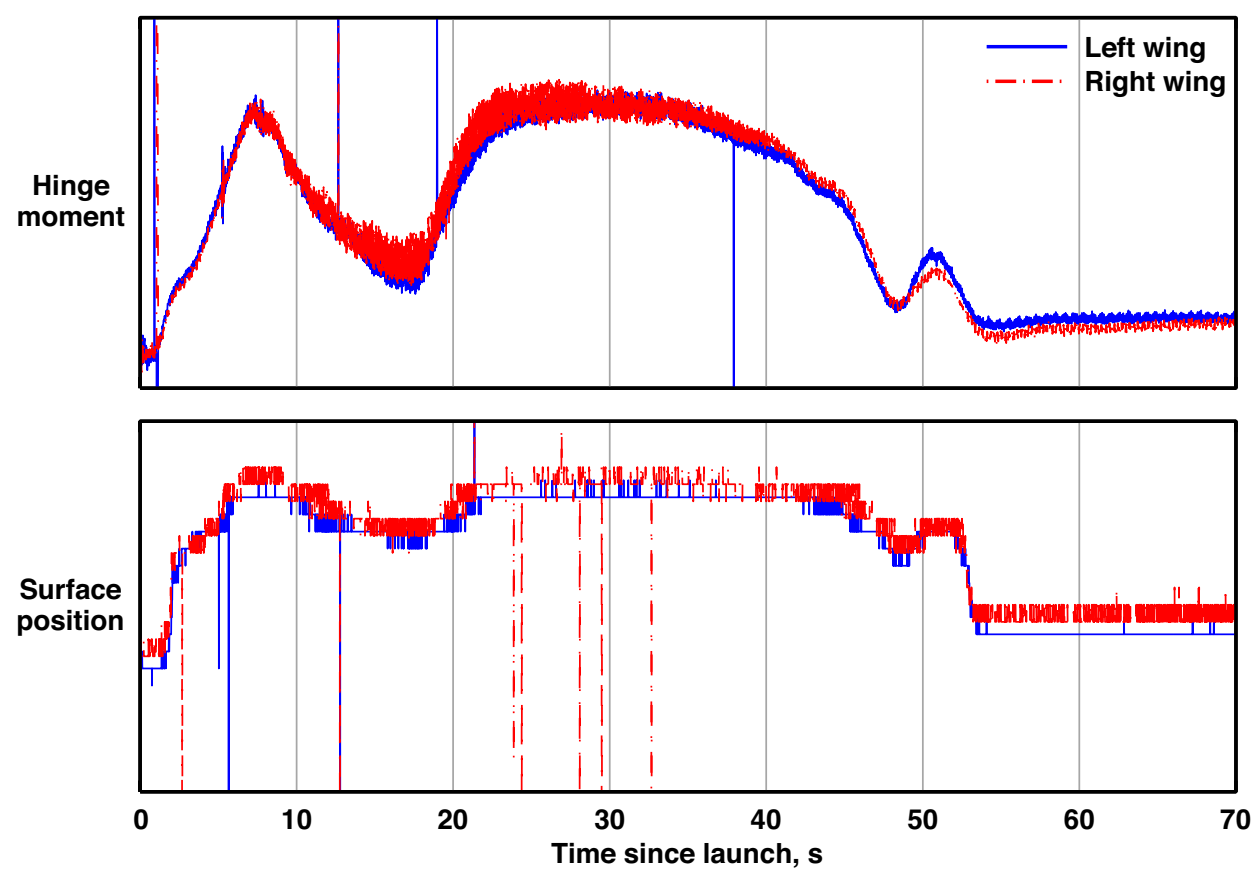

Figure 8. Flight 2 wing hinge moments and positions.

Table 2. Separation condition results.

\begin{tabular}{lccc}
\hline \hline \multicolumn{1}{c}{ Parameter } & Target & $\begin{array}{c}\text { Flight } 2 \\
\text { values }\end{array}$ & Deviation \\
\hline Time to condition & $\leq 100.0 \mathrm{sec}$ & $93.44 \mathrm{sec}$ & $0.0 \mathrm{sec}$ \\
Altitude & $93,932 \mathrm{ft}$ & $94,069 \mathrm{ft}$ & $137 \mathrm{ft}$ \\
Mach* & 7.075 & 6.946 & -0.129 \\
Dynamic pressure* & $1066 \mathrm{psf}$ & $1024 \mathrm{psf}$ & $-42.0 \mathrm{psf}$ \\
Flight path elevation angle & $2.0 \mathrm{deg}$ & $2.4 \mathrm{deg}$ & $+0.4 \mathrm{deg}$ \\
Booster angle of attack & $0.0 \mathrm{deg}$ & $0.08 \mathrm{deg}$ & $+0.08 \mathrm{deg}$ \\
Booster sideslip angle & $0.0 \mathrm{deg}$ & $-0.19 \mathrm{deg}$ & $-0.19 \mathrm{deg}$ \\
\hline \hline
\end{tabular}

* Computed using best estimate atmospheric model.

\section{B. Separation}

Both the software separation logic and the mechanical systems functioned properly, which led to a successful separation. The separation sequence was initiated by the "ready to separate" signal sent from the HXLV to the HXRV. Three seconds after receiving the "ready to separate" signal, the HXRV FMU sent the separate command to the HXLV. The HXLV received the separate command, activated the explosive bolts and pressurized ejector pistons, and successfully separated the X-43A from the RV adapter and HXLV. Figure 9 shows the performance of the starboard RV adapter ejector piston. The piston extension measured by the linear variable differential transformers (LVDT) was well within the predictions from the high fidelity separation simulation. The X-43A successfully separated from the launch vehicle and achieved stable flight. Figure 10 shows images of the separation event taken by the right camera, located in the RV adapter, looking at the aft end of the X-43A. The time between images in the sequence is $33.3 \mathrm{~ms}$. 


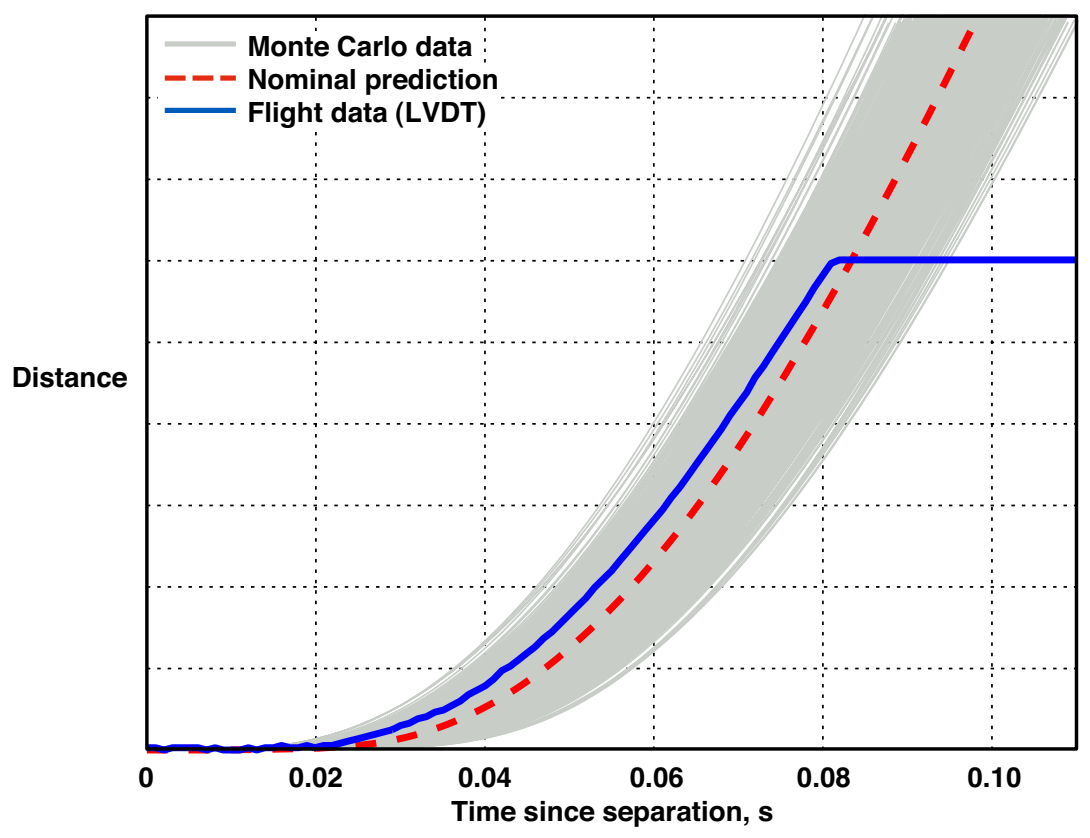

Figure 9. Starboard piston extension.
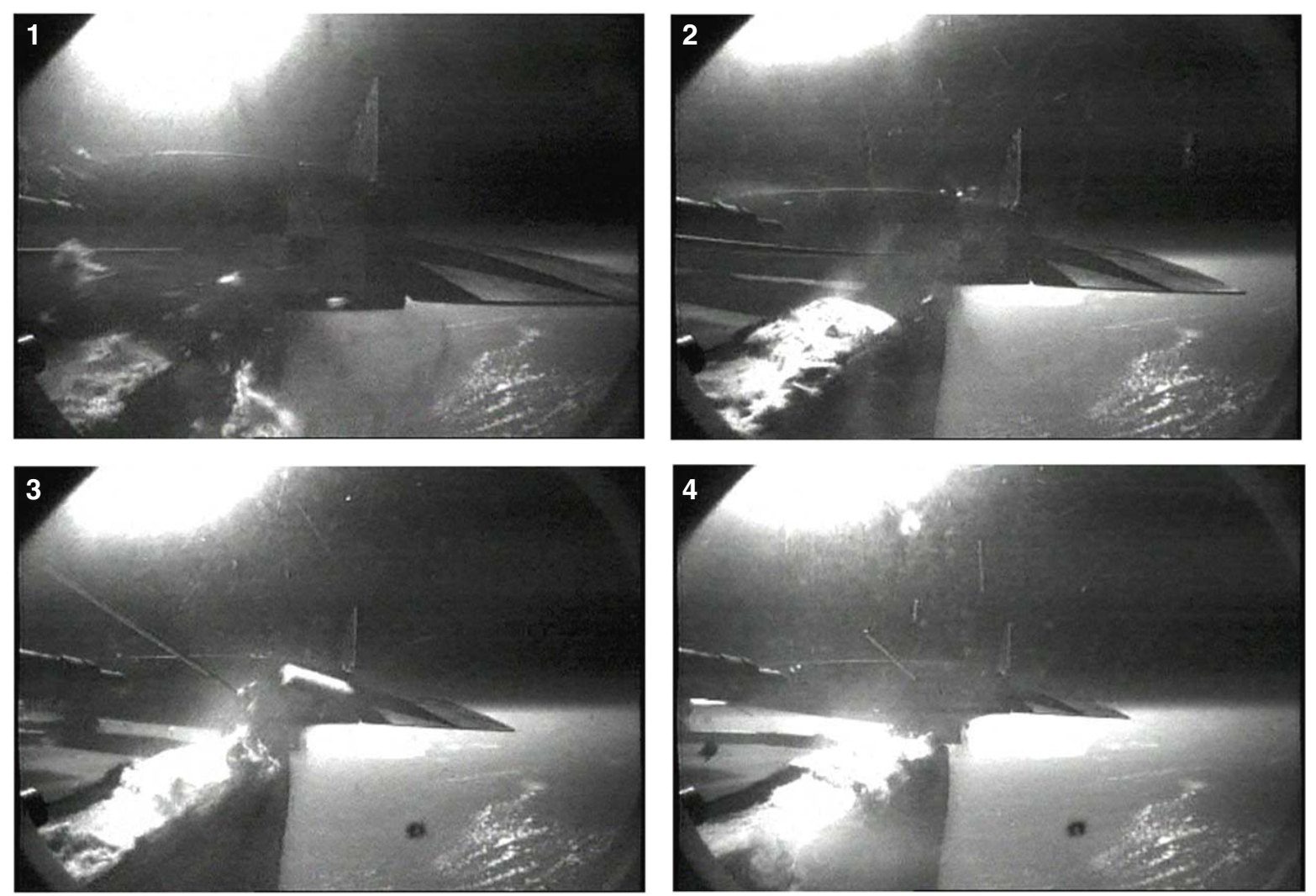

Figure 10. Flight 2 right adapter camera sequence view of aft starboard side of $X-43 A$ during separation. 
During the 2.5-second separation event, the X-43A took longer than predicted to arrive at the required engine test angle of attack as shown in Fig. 11. This has been attributed to a probable miscalculation of the trim pitching moment. The uncertainty model in the separation aerodynamic database did not capture the trim pitching moment uncertainty. ${ }^{6}$ Therefore, analysis performed prior to flight did not predict this behavior. Although the time for the HXRV to arrive at the test angle of attack was longer than predicted, the vehicle arrived at the engine test conditions at the end of the 2.5-second separation event (Fig. 11) as required and therefore did not negatively impact the engine test.

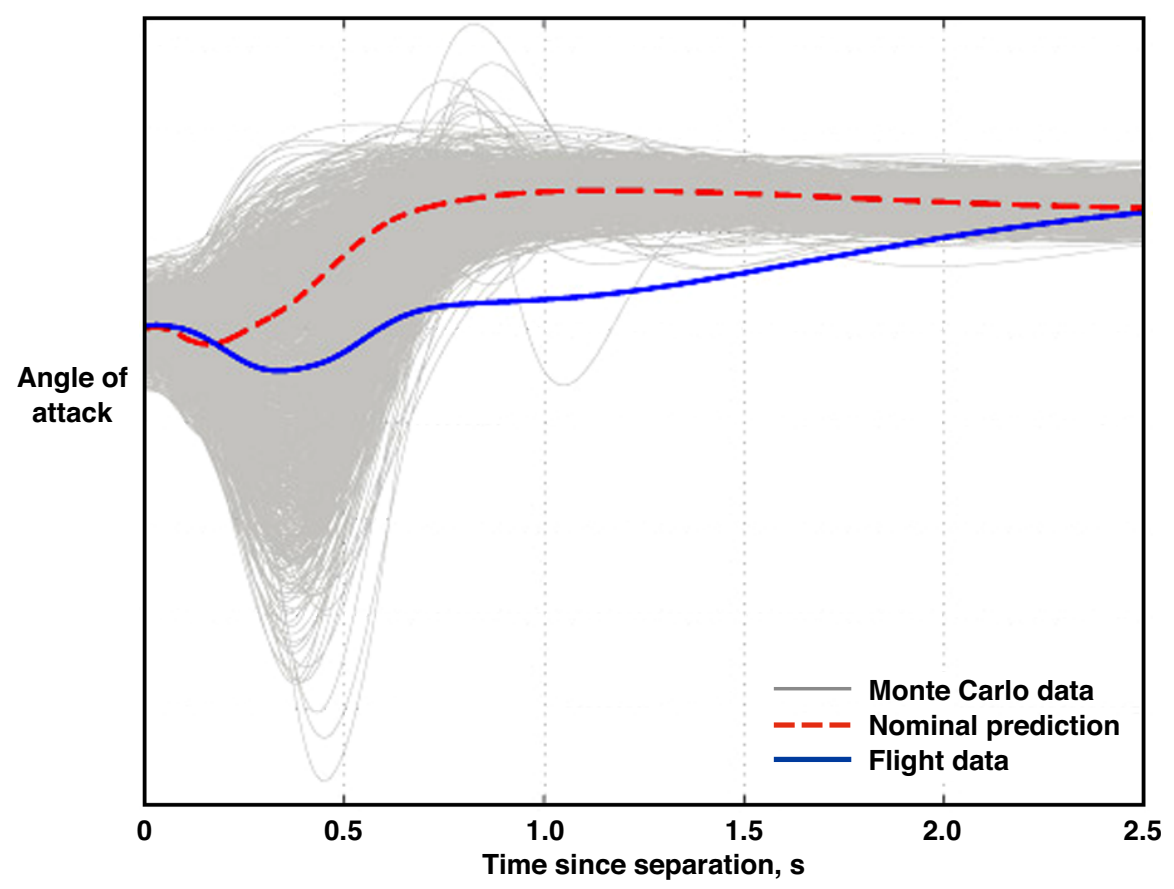

Figure 11. Separation angle of attack.

\section{Engine Experiment}

The scramjet experiment began with the cowl door opening on schedule, 2.5 seconds after separation. When the engine cowl door opened, the X-43A was at the desired engine test conditions. The preexperiment tare was successfully performed and the engine fueling sequence was initiated approximately 5 seconds after the cowl door opened. Both the ignitor and the fuel were delivered to the engine as predicted; the scramjet was fueled for approximately 11 seconds.

During the time the engine was operating, the scramjet did accelerate the vehicle and achieved performance very close to the preflight predictions. Figure 12 shows the approximate flight axial acceleration curve as compared to the nominal and Monte Carlo prediction data. During powered flight, the maximum Mach number achieved was 6.83 and the X-43A flight controls maintained the desired vehicle angle of attack within an acceptable tolerance, as shown in Fig. 13. Following the engine test, the postexperiment tare was performed. Both the cowl open fuel-off (preexperiment and postexperiment) tare pressure data and the fuel-on engine pressure data were compared to the preflight predictions. Figure 14 shows an example of the excellent agreement between the flight data and the predictions. These results substantiate hypersonic engine design tools and flight scaling methodologies, satisfying the primary objective of the Hyper-X program. Prior to closing the scramjet engine cowl door, the vehicle successfully completed the cowl-open PID maneuver.

The thermal environment was similar to what was expected. The airframe and wing structure results, TPS and internal environment were as predicted with the exception of a vertical tail measurement. The vertical tail thermocouple closest to the leading edge experienced temperatures at the upper end of the predicted uncertainty bounds. Another thermocouple in the same area also experienced higher than expected temperatures, but did not exceed the uncertainties. This result points to an as yet unidentified phenomenon not captured by the predictions. The engine experiment and the primary portion of the mission were concluded when the cowl door closed, 39 seconds after separation. 


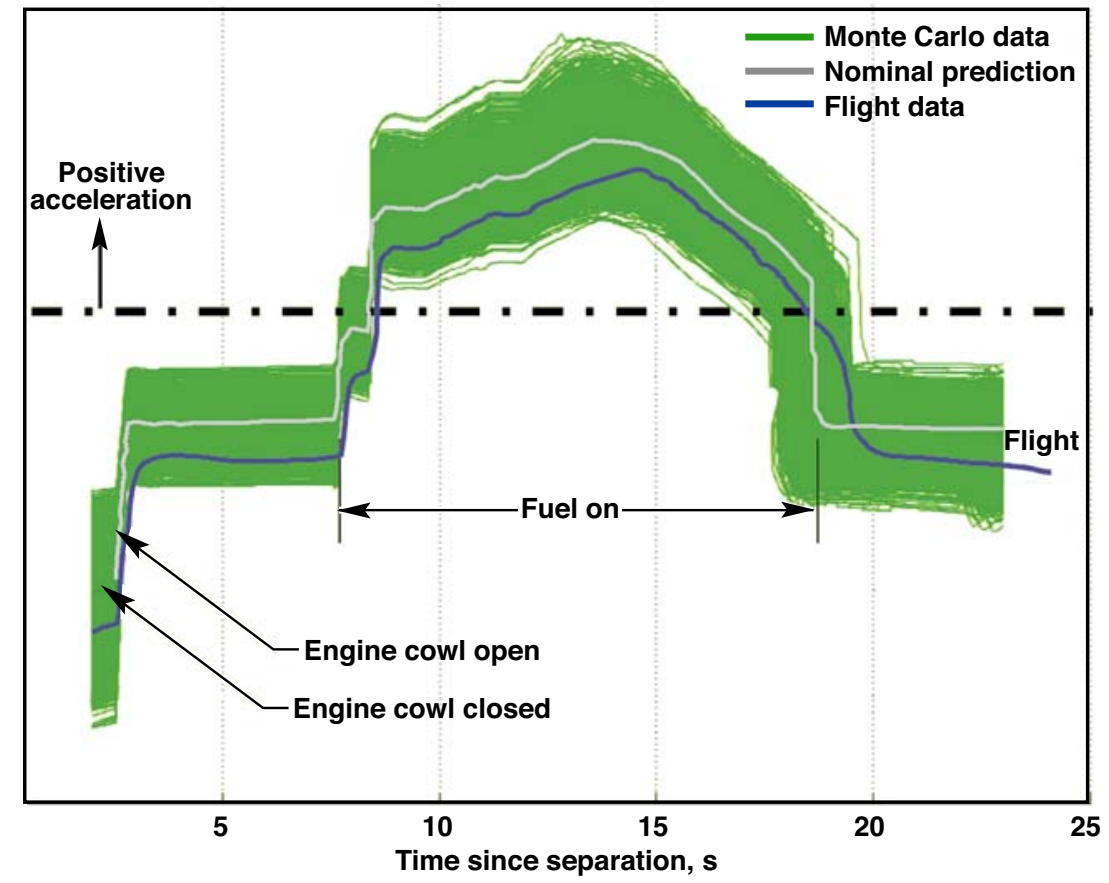

Figure 12. Axial acceleration profile during engine test.

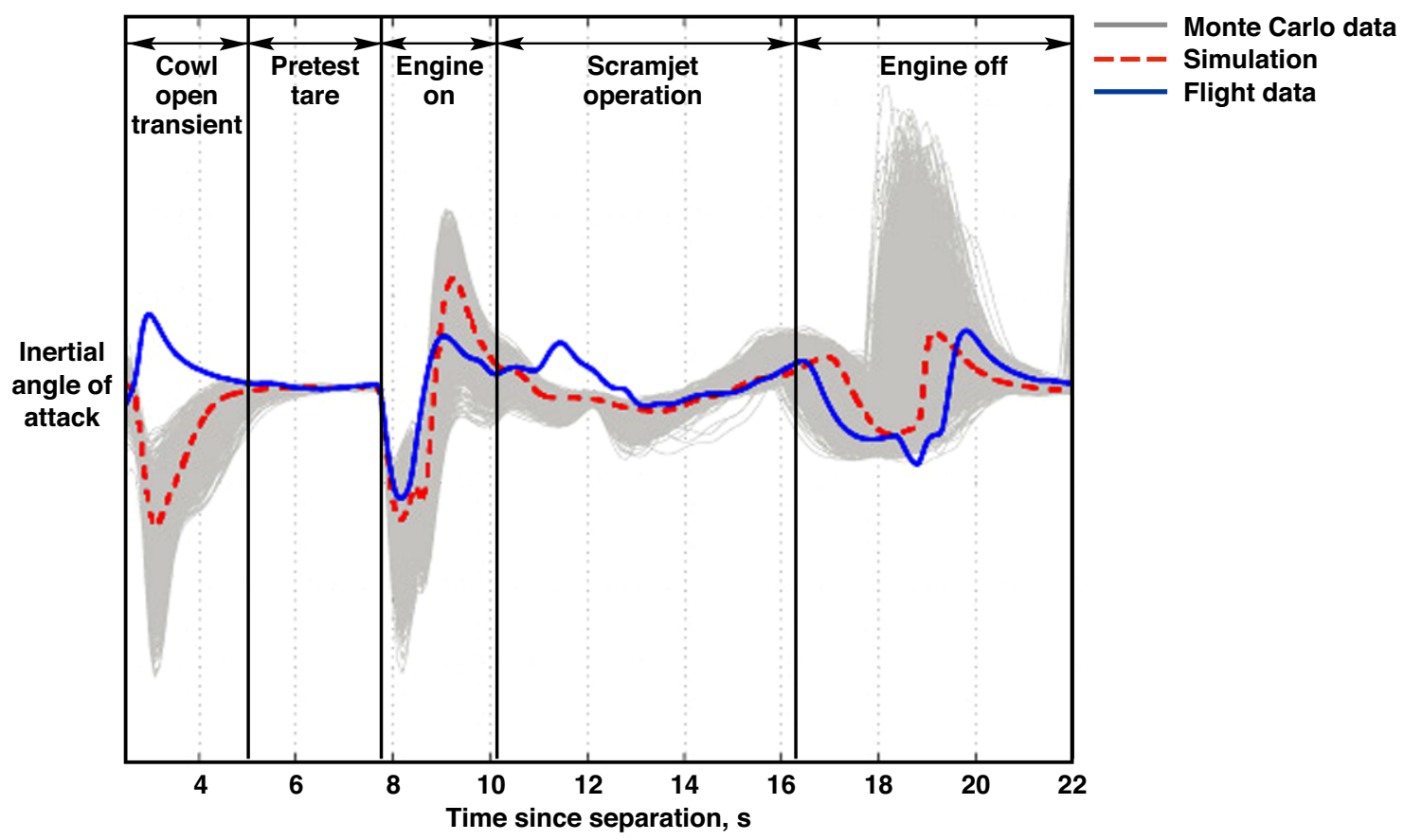

Figure 13. Inertial angle of attack during engine test. 


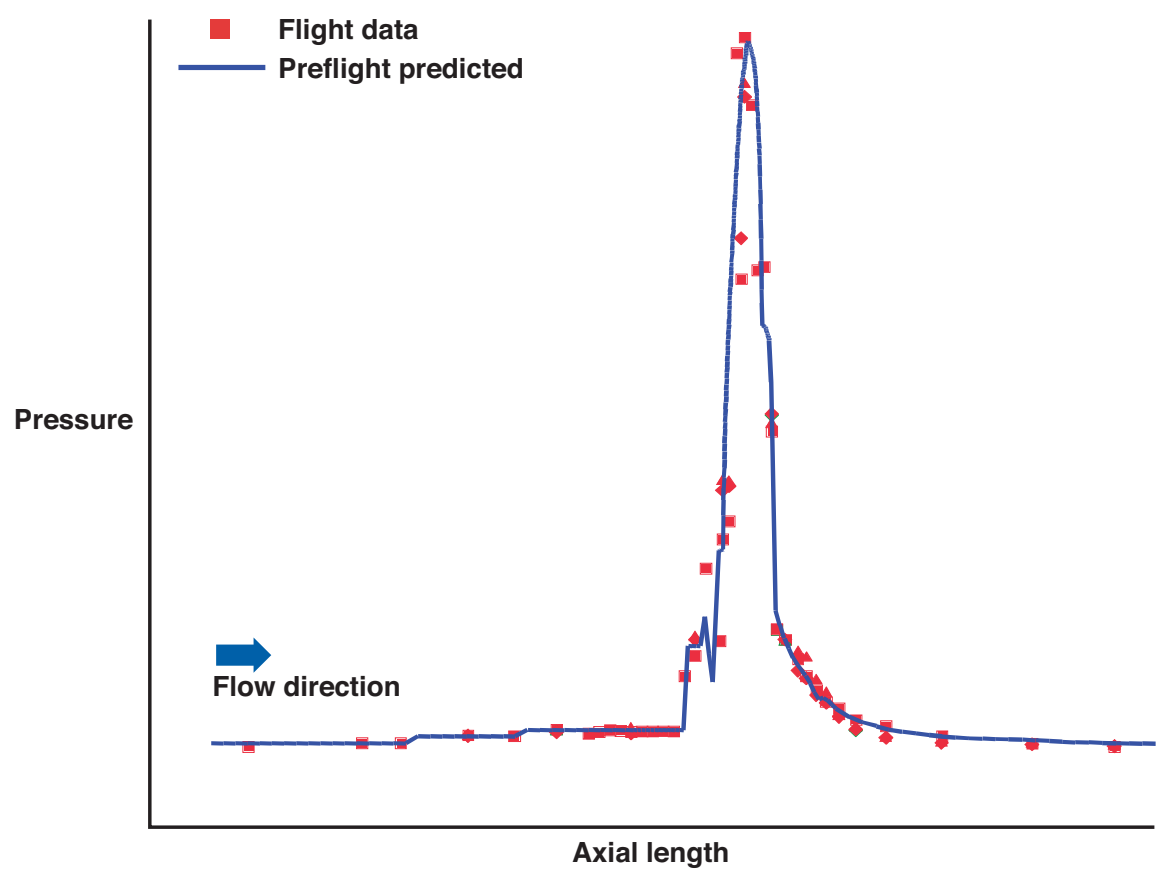

Figure 14. Flight compared to predicted centerline wall pressures.

\section{Descent}

The secondary portion of the mission began when the X-43A increased its angle of attack to initiate the recovery maneuver for beginning the descent. During the recovery maneuver, the X-43A experienced low amplitude angle-of-attack oscillations, shown in Fig. 15 and large spikes in the wing spindle torque readings and actuator currents. Longitudinal aerodynamic parameters, wing spindle friction, wing hinge moments, and shock locations relative to the wing are all being investigated as possible causes for this phenomena. ${ }^{6}$

After the X-43A passed over the horizon and the ground-based assets lost line of sight with the vehicle, the P-3 became the only source of data for the mission. The P-3 reradiated data real-time to the Vandenberg 35-foot dish, which was then transmitted to Pt. Mugu, and finally transmitted to NASA DFRC, so X-43A data were available in the mission control room real-time. However, approximately 176 seconds after separation during the first PID maneuver, the best source selector, responsible for automatically identifying the best telemetry asset (P-3 only at this point in the mission), experienced a polarity change in the telemetry stream and the HXRV signal was lost. The LOS lasted one minute, while the best source selector operators identified the polarity change as the cause of the problem and the data was then restored. This error only affected the data downstream of the best source selector. The data recorded onboard the P-3 was unaffected, so there was no loss of mission data for the X-43A free flight.

During the descent, the vehicle remained controlled and successfully completed all parameter identification maneuvers. In general the actuators responded very well to the commands as shown in Fig. 16, which shows the surface positions and commands for both the rudders and the wings. The PID maneuvers are represented in these figures as the interval surface movements of all surfaces during the descent. The vehicle decelerated quickly, such that the third maneuver sequence began immediately after the second PID maneuvers were complete. 


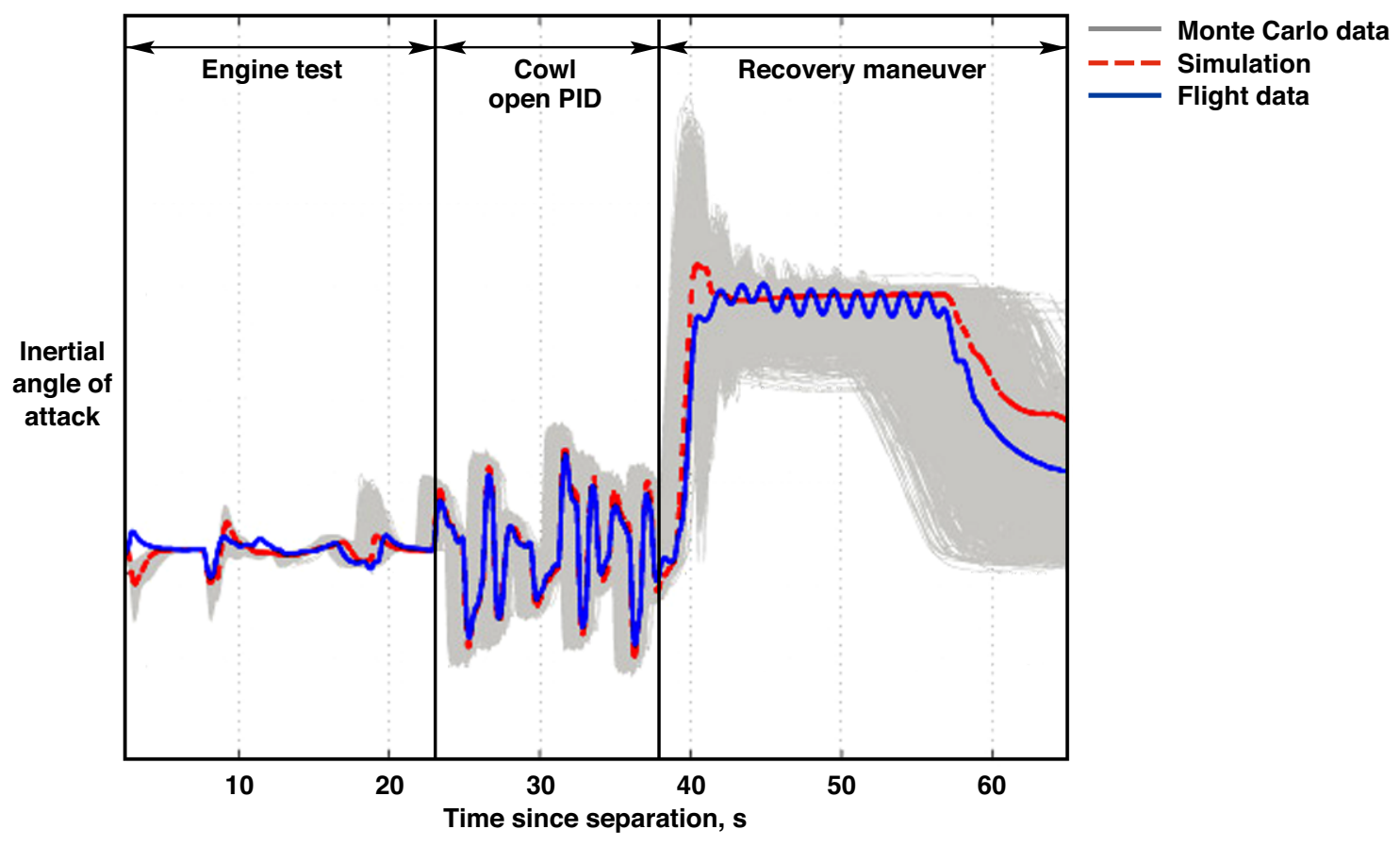

Figure 15. Inertial angle of attack from engine test through the recovery maneuver.
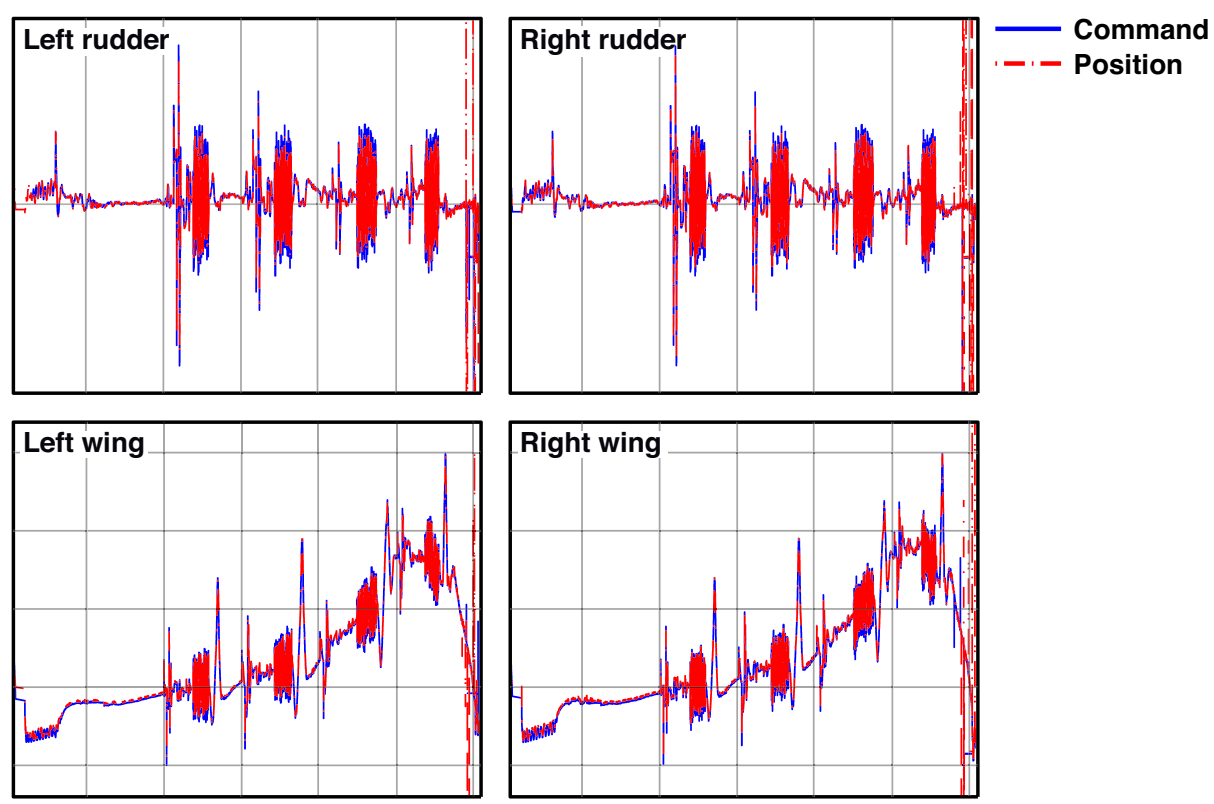

Mach number

Mach number

Figure 16. The $X-43 A$ control surface performance. 
Also during the descent, the X-43A FMU inertial navigation system performed very well. Figures 17(a) and 17(b) show the system performance through comparison of free inertial navigation with GPS and blended navigation solutions for the descent. In all cases there was very good agreement. The discrepancy in Fig. 17(b) between the GPS and inertial east velocities is caused by a known range limit in the GPS velocity.
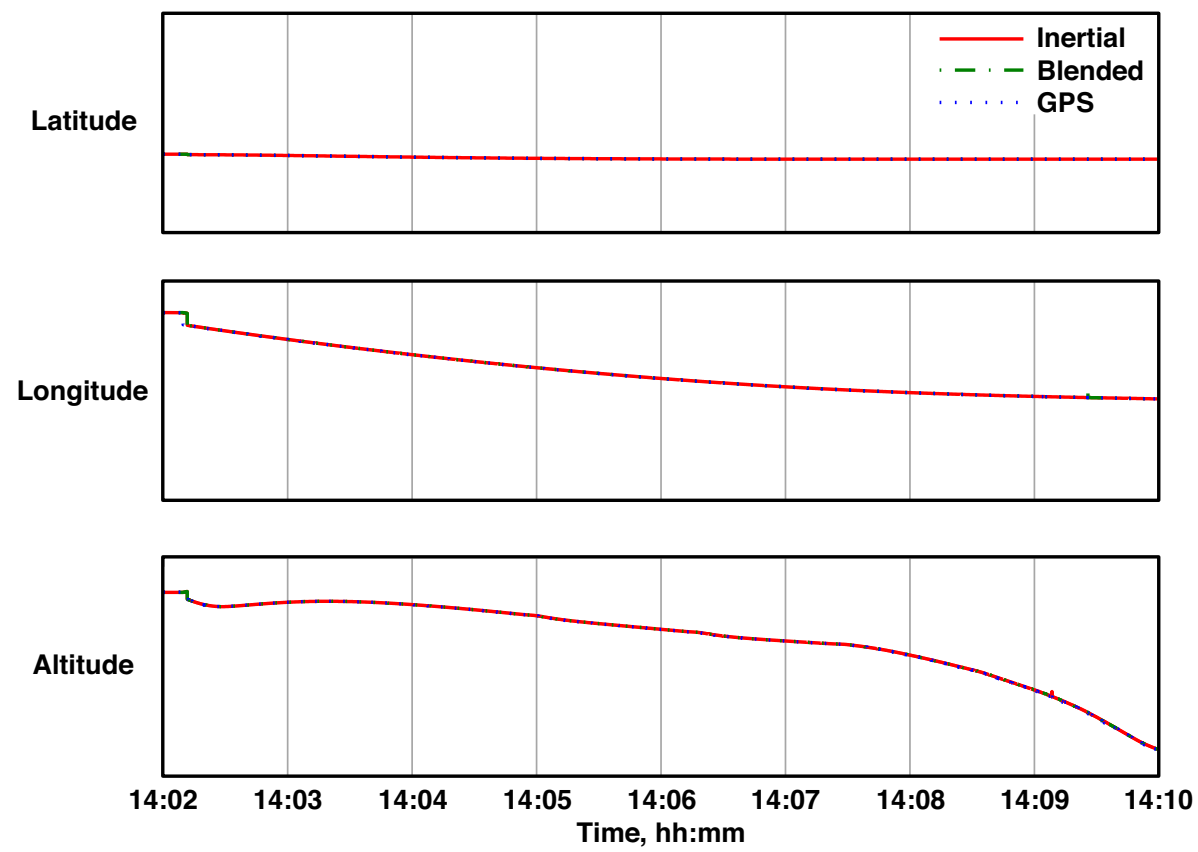

a) Vehicle position.
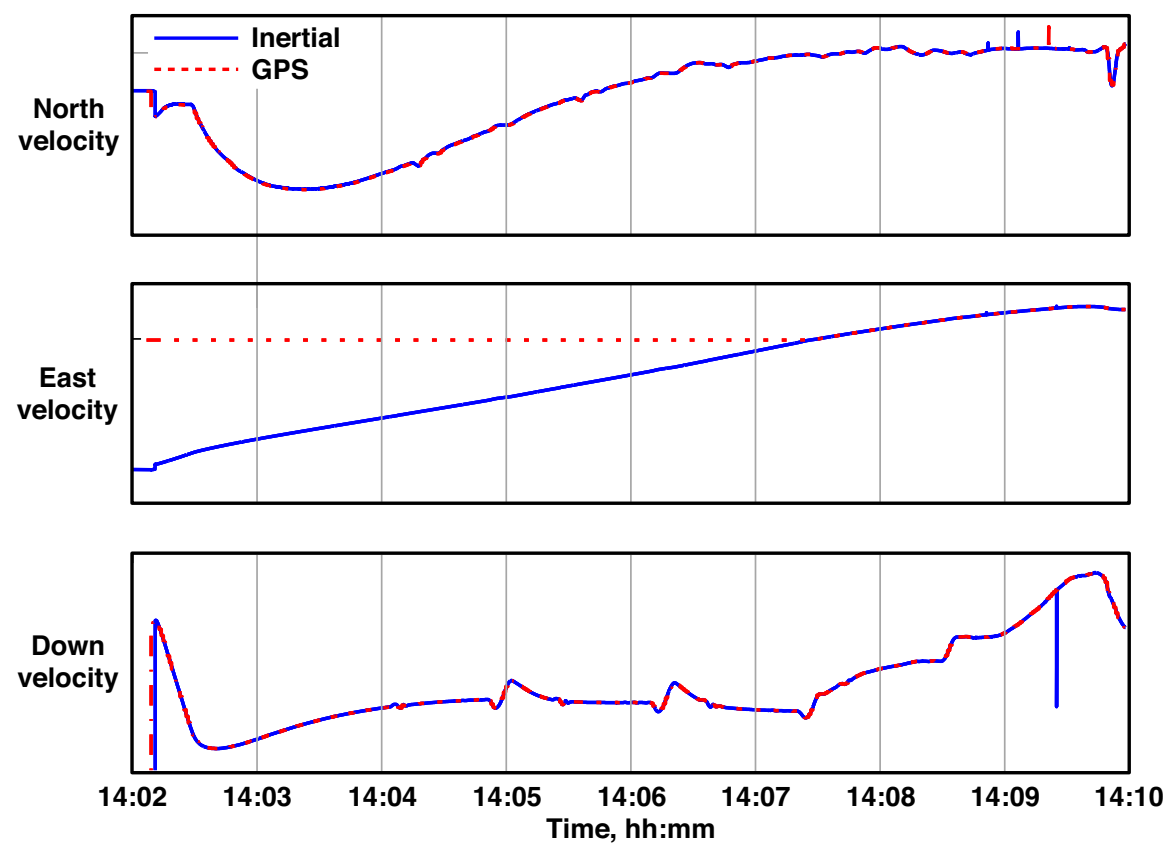

b) Vehicle velocity.

Figure 17. Descent, inertial navigation performance 
Vehicle data was acquired in the descent until a LOS when the X-43A presumably "splashed" into the water. The LOS occurred 508 seconds after separation, approximately $442 \mathrm{nmi}(818 \mathrm{~km})$ from launch. At the time data was lost the X-43A was under control at an altitude of $41.86 \mathrm{ft}(12.76 \mathrm{~m})$, a Mach number of 0.92 , and well within the preflight predictions, as shown in Fig. 18.

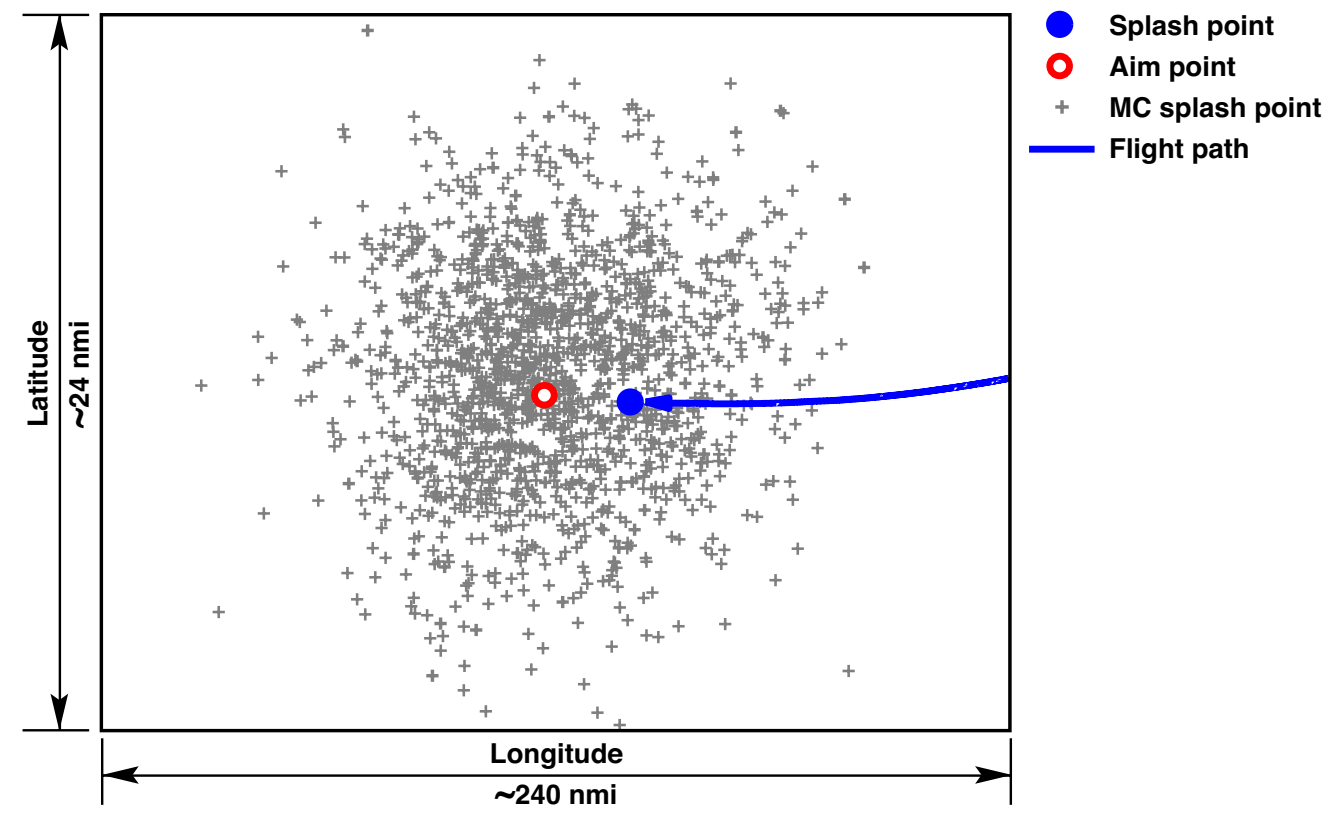

Figure 18. Descent performance, research vehicle splash point.

\section{Lessons Learned}

The preparation for flight 1 , the RTF activities and subsequent preparation for flight 2 presented many challenges, some expected and some unexpected. From these, several lessons were learned and identified.

Changing requirements can be a danger to any project and X-43A was no exception. In the early stages of the project, contractor requirements were defined from the statement of work, as opposed to an all encompassing requirements document. Ultimately, the various requirements and specifications for the project were spread out over three main documents that defined, (1)system and performance, (2)environmental, and (3)instrumentation requirements, respectively. Unfortunately, these documents were revised multiple times, which meant that the team had to continually verify that newly fabricated vehicle systems and components complied with requirements.

The flight systems and performance requirements were typically only defined one vehicle at a time. Although there was a serial aspect of the project, the work was offset at the different facilities. While work on the first vehicle was being performed at NASA DFRC, the second vehicle was being developed and manufactured by ATK GASL and Boeing. This was potentially damaging, with the second vehicle requirements not fully determined and that vehicle in the manufacturing and development phase. Both the scattered requirements and the parallel vehicle processing were caused by an urgency to jump-start the schedule. Although the parallel vehicle processing was an attempt at improving efficiency, in some respects it had the opposite effect. If the project had had a dedicated discipline team for each vehicle, several issues including creeping requirements and parallel vehicle processing could have been resolved.

The X-43A utilized many unique components designed specifically for the vehicle. In some cases there were commercial off-the-shelf (COTS) components that appeared to meet the requirements and theoretically could be used with very little additional effort. Unfortunately this was not always the case. Several of these components needed a lot of development. As a result, it was determined that there are not "off-the-shelf" components for this class of vehicle, i.e. single string, expendable, high-temperature, and high-vibration environment. The time spent adapting the COTS components was time that could have been dedicated to other aspects of the mission. Furthermore, even though a component or part is proven, that doesn't mean it is a viable option for the specific task. COTS parts should be evaluated for suitability for each desired application. 
Several of the lessons learned from flight 1 were derived from the way in which the project operated through the return to flight and preparation for flight 2 . The IPT and lead structure within the disciplines was invaluable. This same structure should apply to the project as a whole. Those responsible for the specific vehicle or event should monitor that closely, but those responsible for the coordination effort and bringing all the pieces together should monitor all aspects of the project or discipline, not just the primary objective. In the case of the Hyper-X project, NASA had the responsibility for coordinating the effort. As a result, prior to flight 1 , time should have been spent monitoring all aspects of the project, as was done for flight 2 preparation, not just the research vehicle.

In the preparation for flight 2 , a fair amount of time and effort was spent on the non-X-43A-specific components or events, such as the B-52, HXLV, and boost trajectory. It is important to bear in mind when proceeding forward with a project of this magnitude that sometimes solving the research problem means having to solve the problems along the way that may or may not be directly related to the research. In the case of the X-43A, the project was built around an engine and the desire to demonstrate that scramjet engine technology was feasible in hypersonic aircraft. But since the engines targeted two key flight conditions respectively, other means were required to get to the engine test point. Even with the launch vehicle identified, there was still the requirement for a means to air-launch the Hyper-X stack. The age of the B-52 and the difficulty to obtain parts presented additional difficulties, which the flight schedule did not take into account. Nor did it account for the failure of the first flight. A success-oriented schedule will only get a project so far. If the project schedule is used to gauge necessary funding and personnel, the success-oriented schedule can yield under estimates that could be damaging. The initial program schedule had flight 2 being completed on October 30,2000, as opposed to March 27, 2004. Even during the course of the project, when schedules were updated and reestimated, the estimates fell short of the actual dates. For example, the flight 1 schedule was updated in June 2000 to reflect an October 2, 2000 flight date, as opposed to the actual flight date, June 2, 2001.

\section{Concluding Remarks}

After the excruciating pain of the first flight failure, the struggle to identify the cause during the mishap investigation, and the years of improvements implemented during the return to flight effort, the success of the X-43A Mach 7 flight was well deserved.

The second flight of the X-43A demonstrated that scramjets can work at conditions up to Mach 6.83 at an altitude of $94,000 \mathrm{ft}(28.7 \mathrm{~km})$. The X-43A project broadened the extent of the scramjet operational database and gave confidence that vehicles of this type could be designed and flown successfully. As with any major project some unforeseen events occurred in the preparation phase, these were handled well and lessons were learned from them. Although the primary objective was met; to demonstrate and validate the technology, the experimental techniques, and the design tools; some anomalous events occurred during the flight which demonstrate the necessity for flight research. The successes of both this project and the second flight are attributed to the processes for design, development, and testing; the perseverance of the project team in the face of failure; the strong foundation based on flight 1 experience; MIB findings and recommendations; and the teamwork between NASA, ATK GASL, Boeing, and Orbital Sciences Corporation.

\section{References}

${ }^{1}$ Freeman, D. C., Jr., Reubush, D. E., McClinton, C. R., Rausch, V. L., and Crawford, J. L., “The NASA Hyper-X Program,” NASA TM-1997-207243, 1997.

${ }^{2}$ Reubush, D. E., "Hyper-X Stage Separation-Background and Status," $9^{\text {th }}$ International Space Planes and Hypersonic Systems and Technologies Conference, AIAA99-4818, Norfolk, VA, November 1-5, 1999.

${ }^{3}$ Hunt, J. L., Eiswirth, E. A., "NASA's Dual-Fuel Airbreathing Hypersonic Vehicle Study," $7^{\text {th }}$ International Space Planes and Hypersonic Systems and Technology Conference, AIAA-1996-4591, Norfolk, VA, November 18-22, 1996.

${ }^{4} \mathrm{X}-43 \mathrm{~A}$ Mishap Investigation Board, Report of Findings X-43A Mishap, May 8, 2003. On the web at www.nasa.gov/pdf/47414main_x43A_mishap.pdf

${ }^{5}$ Huebner, L. D., Rock, K. E., Ruf, E. G., Witte, D. W., "Hyper-X Flight Engine Ground Testing for X-43 Flight Risk Reduction," AIAA/NAL-NASDA-ISAS $10^{\text {th }}$ International Space Planes and Hypersonic Systems and Technologies Conference, AIAA 2001-1809, Kyoto, Japan, April 24-27, 2001.

${ }^{6}$ Bahm, C., Baumann, E., Martin, J., Bose, D., Beck, R., and Strovers, B., "The X-43A Hyper-X Mach 7 Flight 2 Guidance, Navigation, and Control Performance," AIAA-2005-3275, AIAA/CIRA $13^{\text {th }}$ International Space Planes and Hypersonic Systems and Technologies Conference, Capua, Italy, May 16-20, 2005. 